\title{
Effect of Variable Core Stiffness on the Impact Response of Curved Sandwich Plates
}

\author{
B. Arachchige, H. Ghasemnejad ${ }^{1}$ \\ ${ }^{1}$ Centre for Structures, Assembly and Intelligent Automation, \\ Cranfield University, MK43 0AL, UK
}

\begin{abstract}
.
An extensive analytical model to determine behaviour of curved sandwich plates with variable stiffness cores and face-sheets under low velocity impact with foam core is presented in this paper. A developed method is introduced to determine effective dynamic stiffness of the facesheets and core with variable stiffness. A modified spring-mass-dashpot model was used to obtain the contact force function related to effective dynamic stiffness and effective dynamic frequency to determine the contact force histories by impact of a hemispherical-nose impactor. A parametric study was also performed to understand the effects of several factors such as impactor velocity, face-sheet thickness, core thickness (constant and variable stiffness), layup orientation and curvature on the contact force histories of curved sandwich plates. Different geometries of curved sandwich plates are analysed to study their performance under impact loading. Numerical analysis was performed in LS-DYNA to further validate with the developed analytical models.
\end{abstract}

Keywords: Analytical; Impact; Variable Stiffness; Sandwich, LSDYNA

\section{Nomenclature}

E Young's Modulus (GPa)

$G_{12} \quad$ Shear Modulus (GPa)

$\gamma \quad$ Poisson's ratio of plate/impactor

$\rho \quad$ Density of plate/impactor

\footnotetext{
${ }^{1}$ Corresponding Author: email: Hessam.Ghasemnejad@cranfield.ac.uk Tel.:+44 (0) 1234754395. Centre for Structures, Assembly and Intelligent Automation, Cranfield University, MK43 0AL, UK.
} 
b Width of plate

$\mathrm{M}_{0} \quad$ Mass of impactor

a Length of plate

$D_{1 d} \quad$ Dynamic bending of facesheet

$\mathrm{G}_{13} \quad$ Shear modulus of core

h Total thickness of facesheet

$h_{k} \quad$ Thickness of ply

$\mathrm{H} \quad$ Height of core

$K_{g d_{e f}} \quad$ Effective dynamic global stiffness of simply supported panel

$K_{1 d_{e f}} \quad$ Effective dynamic local stiffness of top face sheet

$m_{f} \quad$ Effective mass of top facesheet

$Q_{d} \quad$ Total dynamic core crushing strength

$A_{44 s}, A_{55 s}=G_{13} H$ Transverse shear stiffness of sandwich

$\delta \quad$ Local indentation of top face-sheet

$\Delta \quad$ Global plate bending

$m_{s} \quad$ Mass of sandwich plate

$M_{0} \quad$ Mass of impactor

$R_{1}, R_{2} \quad$ Radiuses of plate

$\omega_{m n} \quad$ Natural frequency of face-sheet

$M_{f} \quad$ Mass of face-sheet

$D_{i j s} \quad$ Sandwich bending stiffness matrix

$P \quad$ Indentation force 


\section{Introduction}

Sandwich structures with honeycomb or foam cores are widely used in aerospace, marine, automotive applications mainly due to the advantages such as greater strength and stiffness, increased energy absorption and corrosion resistance. These structures experience low velocity impact events caused by tool drops, runway stones, hails, etc, thus reducing the strength of the structure [1-2]. Therefore, accurate prediction of the impact response of sandwich structures is vital in aerospace industry.

It was observed that most researches on the impact behaviour of sandwich panels were either numerical or experimental. Few analytical models have been developed, since modelling the interactions between the facesheets and core during impact is a complex process [3]. Abrate [4] outlines analytical modelling approaches to model impact on sandwich panels by incorporating contact laws, plate theories and dynamic mass-spring systems.

Hoo Fatt and Park [3] used single and multi-degree of freedom systems to predict the impact response of sandwich panels subjected to various boundary conditions. An analytical force function to determine the impact response of simply supported and clamped panels were derived. The analytical solutions matched well with the experimental work on flat sandwich panels. However, this work was limited to impact response flat sandwich plates. In another work [5] they investigated the failure modes associated with sandwich panels and derived that the main failure modes associated are core shear failure, shear and top face-sheet failure and bottom face-sheet tensile failure.

Malekzadeh et al. [6] adopted an improved higher order sandwich plate theory (IHASAPT) to predict the low velocity impact of sandwich panels that comprised of a transversely flexible core and composite face-sheets. Analytical solutions for the contact force histories and deflection of the panel were developed through a new system consisting of spring-massdamper-dashpot or spring-mass-damper.

Drop weight impact tests on glass/polyester sandwich panels were performed by Caprino et al. [7] and effects of different core densities and core thicknesses on the impact histories were examined. Similar studies were carried out by Anderson [8] to compare analytical predictions with experimental work for different facesheet and core arrangements. 
Crushing of the core and large deflections of the facesheet were incorporated by Olsson and McManus [9] in their analytical model. In another study, Olsson [10] suggested a method for the prediction of impact response and damage in sandwich panels considering the effects of core crushing, delamination and large deflections of the facesheet. Studies on the bending behaviour of sandwich beams were conducted by Frosting et al [11-12] by using the higher order theory.

The effect of impactor shape on the impact response of foam core sandwich panels were studied by Flores-Johnson and Li [13]. They showed that the impact behaviour of sandwich panels were largely affected by the shape of the impactor and the density of the foam core. Hosseini et al [14] analytically studied impact response of sandwich panels with rigid plastic core and constant stiffness face-sheets.

Zhou and Stronge [15] derived analytical solutions for circular sandwich panels impacted by a spherical indenter. According to their results denting depends on the kinetic energy, compliance and nose shape of the colliding body as well as the compliance and mass density of the sandwich panel. Yurddaskal and Baba [16] studied curvature effects on impact response of sandwich panels. They discovered that contact force increases as impact energy increases for flat and curved plates and that curved plates exhibit more damage at the upper face-sheet. Arachchige et al. [17] derived analytical solutions by using first order shear deformation theory to analyse low velocity impact response of variable stiffness curved composite plate. Their method was based on calculating natural frequency of the plate under impact and this method has been used in this study to determine natural frequencies of the variable stiffness face-sheets in the sandwich plate in the present work. Feng et al. [18] performed low velocity impact tests on sandwich panels with graphite/epoxy skins and PVC foam cores. They found that higher core densities resulted in stiffer force-displacement curves and higher peak loads.

Review of these works suggested that a study related to analysis of low velocity impact on a curved sandwich plate with variable stiffness face-sheets and cores were necessary since most of structural applications consist of variable thicknesses within their structures; and it is therefore required to evaluate the behaviour of such structures under impact loading. The stiffness variation is achieved by variation in thickness of either face-sheet or core section. The present study develops an analytical model for a curved sandwich panel with variable facesheet thicknesses and variable stiffness foam core with constant transverse crushing resistance. A developed approach introduces a dynamic stiffness of facesheets and core to analyse sandwich 
plate geometries with variable stiffness face-sheets and core sections. This analytical model is also applicable for studying impact response of doubly curved sandwich plates. Different cases of sandwich plate geometries are analysed to study their response under low velocity impact. Numerical models are also developed in LSDYNA for validation of analytical models for both constant stiffness core and variable stiffness core sandwich plates. Therefore, this analytical model would serve as a useful tool for future design of curved sandwich structures.

\section{Analytical models}

A curved sandwich plate with dimensions, length $a$, width, $b$ and radius, $R_{1}$ is impacted in the centre by a rigid hemispherical nose cylinder with radius $\mathrm{R}$ and length, L (see Figure 1(a)). Different sandwich plate geometries which are studied in this research are shown in Figure 1a, $1 \mathrm{~b} \& 1 \mathrm{c}$.
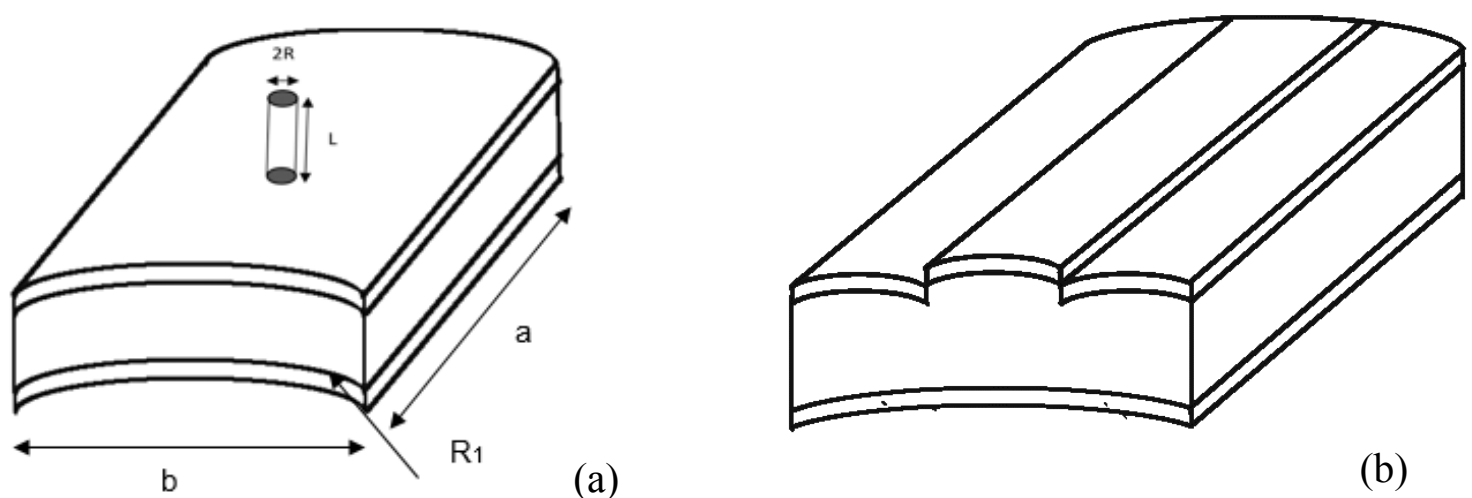

(a)

(b)
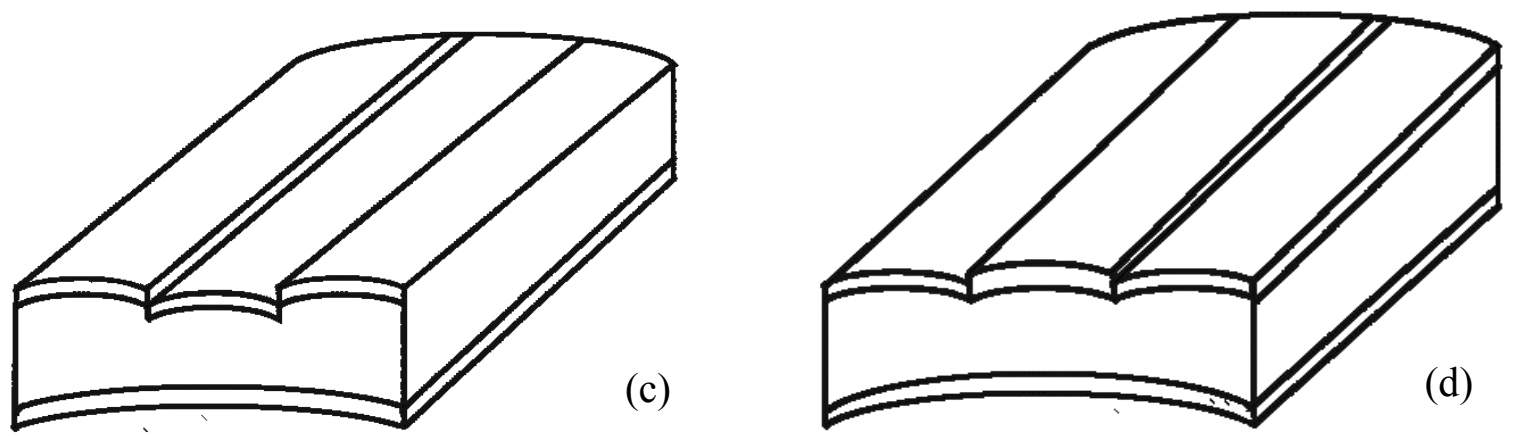

Figure 1. Idealised modes of curved sandwich plates (a) constant stiffness facesheets and core model (b) and (c) variable stiffness core, constant stiffness facesheet model, (d) variable stiffness top facesheet, constant stiffness core model subjected to central impact. 


\section{Theoretical formulations}

In this research, studying the impact response of curved composite sandwich plates involves relating natural frequency of the top face-sheet and effective frequency of whole sandwich plate to derive the contact force function. First order shear deformation theory is used to express the equations of motion in a symmetric laminate. Then, double Fourier series is used to solve the equations to define Fourier coefficients for the impact problem. The effect of curvature is also included in the formulation. These formulations are also applicable for doubly curved sandwich plates.

Equations of motion of the symmetric composite laminate is expresses as [19]:

$$
\begin{aligned}
& A_{11}\left(\frac{\partial^{2} u_{0}}{\partial x_{1}^{2}}+\frac{1}{R_{1}} \frac{\partial w_{0}}{\partial x_{1}}\right)+A_{12}\left(\frac{\partial^{2} v_{0}}{\partial x_{1} \partial x_{2}}+\frac{1}{R_{2}} \frac{\partial w_{0}}{\partial x_{1}}\right)+A_{66}\left(\frac{\partial^{2} v_{0}}{\partial x_{1} \partial x_{2}}+\frac{\partial^{2} u^{0}}{\partial x_{2}^{2}}\right)+c_{0} D_{66}\left(\frac{\partial^{2} \varphi_{1}}{\partial x_{2}^{2}}+\right. \\
& \left.\frac{\partial^{2} \varphi_{2}}{\partial x_{1} \partial x_{2}}\right)+k_{s h} A_{55}\left(\frac{\varphi_{1}}{R_{1}}+\frac{1}{R_{1}} \frac{\partial w_{0}}{\partial x_{1}}-\frac{u_{0}}{R_{1}^{2}}\right)+\frac{\partial N_{11}^{i}}{\partial x_{1}}+\frac{N_{11}^{i}}{R_{1}}\left(\frac{\partial w_{0}}{\partial x_{1}}-\frac{u_{0}}{R_{1}}\right)-I_{0} \frac{\partial^{2} u_{0}}{\partial t^{2}}-I_{1} \frac{\partial^{2} \varphi_{1}}{\partial t^{2}}=0
\end{aligned}
$$

$$
\begin{aligned}
& A_{12}\left(\frac{\partial^{2} u_{0}}{\partial x_{1} \partial x_{2}}+\frac{1}{R_{1}} \frac{\partial w_{0}}{\partial x_{2}}\right)+A_{22}\left(\frac{\partial^{2} v_{0}}{\partial x_{2}^{2}}+\frac{1}{R_{2}} \frac{\partial w_{0}}{\partial x_{2}}\right)+A_{66}\left(\frac{\partial^{2} u_{0}}{\partial x_{1}^{2}}+\frac{\partial^{2} u_{0}}{\partial x_{1} \partial x_{2}}\right)+\left[k _ { s h } A _ { 4 4 } \left(\frac{\varphi_{2}}{R_{2}}+\frac{1}{R_{2}} \frac{\partial w_{0}}{\partial x_{2}}-\right.\right. \\
& \left.\left.\frac{v_{0}}{R_{2}^{2}}\right)\right]-c_{0} D_{66}\left(\frac{\partial \varphi_{1}}{\partial x_{1} \partial x_{2}}+\frac{\partial \varphi_{2}}{\partial x_{1}^{2}}\right)+\frac{\partial N_{22}^{i}}{\partial x_{2}}+\frac{N_{22}^{i}}{R_{2}}\left(\frac{\partial w_{0}}{\partial x_{2}}-\frac{v_{0}}{R_{2}}\right)=I_{0} \frac{\partial^{2} v_{0}}{\partial t^{2}}+\frac{\partial^{2} \varphi_{2}}{\partial t^{2}}
\end{aligned}
$$

$$
k_{s h} A_{55}\left(\frac{\partial^{2} w_{0}}{\partial x_{1}^{2}}+\frac{\partial \varphi_{1}}{\partial x_{1}}-\frac{1}{R_{1}} \frac{\partial u_{0}}{\partial x_{1}}\right)+k_{s h} A_{44}\left(\frac{\partial^{2} w_{0}}{\partial x_{2}^{2}}+\frac{\partial \varphi_{2}}{\partial x_{2}}-\frac{1}{R_{2}} \frac{\partial v_{0}}{\partial x_{2}}\right)-\frac{1}{R_{1}}\left\{A_{11}\left(\frac{\partial u_{0}}{\partial x_{1}}+\frac{w_{0}}{R_{1}}\right)+\right.
$$$$
\left.A_{12}\left(\frac{\partial v_{0}}{\partial x_{2}}+\frac{w_{0}}{R_{2}}\right)\right\}+\frac{1}{R_{2}}\left\{A_{12}\left(\frac{\partial u_{0}}{\partial x_{1}}+\frac{w_{0}}{R_{1}}\right)+A_{22}\left(\frac{\partial v_{0}}{\partial x_{2}}+\frac{w_{0}}{R_{2}}\right)\right\}+\frac{\partial}{\partial x_{1}}\left[N_{11}^{i}\left(\frac{\partial w_{0}}{\partial x_{1}}-\frac{u_{0}}{R_{1}}\right)\right]+
$$$$
\frac{\partial}{\partial x_{2}}\left[N_{22}^{i}\left(\frac{\partial w_{0}}{\partial x_{2}}-\frac{v_{0}}{R_{2}}\right)\right]+q=I_{0} \frac{\partial^{2} w_{0}}{\partial t^{2}}
$$

$$
\begin{aligned}
& D_{11}\left(\frac{\partial^{2} \varphi_{1}}{\partial x_{1}^{2}}\right)+D_{12}\left(\frac{\partial^{2} \varphi_{2}}{\partial x_{1} \partial x_{2}}\right)+D_{66}\left(\frac{\partial^{2} \varphi_{2}}{\partial x_{1} \partial x_{2}}+\frac{\partial^{2} \varphi_{1}}{\partial x_{2}^{2}}\right)-\left[k_{s h} A_{55}\left(\varphi_{1}+\frac{\partial w_{0}}{\partial x_{1}}-\frac{u_{0}}{R_{1}}\right)\right]=I_{2} \frac{\partial^{2} \varphi_{1}}{\partial t^{2}}+ \\
& I_{1} \frac{\partial^{2} u_{0}}{\partial t^{2}}
\end{aligned}
$$

$$
\begin{aligned}
& D_{66}\left(\frac{\partial^{2} \varphi_{1}}{\partial x_{1} \partial x_{2}}+\frac{\partial^{2} \varphi_{2}}{\partial x_{1}^{2}}\right)+D_{12}\left(\frac{\partial^{2} \varphi_{1}}{\partial x_{1} \partial x_{2}}\right)+D_{22}\left(\frac{\partial^{2} \varphi_{2}}{\partial x_{2}^{2}}\right)-\left[k_{s h} A_{44}\left(\varphi_{2}+\frac{\partial w_{0}}{\partial x_{2}}-\frac{v_{0}}{R_{2}}\right)\right]=I_{2} \frac{\partial^{2} \varphi_{2}}{\partial t^{2}}+ \\
& I_{1} \frac{\partial^{2} v_{0}}{\partial t^{2}}
\end{aligned}
$$


Deflections and rotations of a flat composite plate using Double Fourier series are expressed as:

$$
\begin{aligned}
& u_{0}\left(x_{1}, x_{2}, t\right)=\sum_{n=1}^{\infty} \sum_{m=1}^{\infty} U_{m n}(t) \cos \frac{m \pi x_{1}}{a} \sin \frac{n \pi x_{2}}{b} \\
& v_{0}\left(x_{1}, x_{2}, t\right)=\sum_{n=1}^{\infty} \sum_{m=1}^{\infty} V_{m n}(t) \sin \frac{m \pi x_{1}}{a} \sin \frac{n \pi x_{2}}{b} \\
& w_{0}\left(x_{1}, x_{2}, t\right)=\sum_{n=1}^{\infty} \sum_{m=1}^{\infty} W_{m n}(t) \sin \frac{m \pi x_{1}}{a} \sin \frac{n \pi x_{2}}{b} \\
& \varphi_{1}\left(x_{1}, x_{2}, t\right)=\sum_{n=1}^{\infty} \sum_{m=1}^{\infty} X_{m n}(t) \cos \frac{m \pi x_{1}}{a} \sin \frac{n \pi x_{2}}{b} \\
& \varphi_{2}\left(x_{1}, x_{2}, t\right)=\sum_{n=1}^{\infty} \sum_{m=1}^{\infty} Y_{m n}(t) \sin \frac{m \pi x_{1}}{a} \cos \frac{n \pi x_{2}}{b}
\end{aligned}
$$

In equations [6] to [10], $a$ and $b$ represents the length and width of the plate respectively and $U_{m n}, V_{m n}, W_{m n}, X_{m n}, Y_{m n}$ are the time-dependant constants that needs to be evaluated.

The terms of the Fourier series can be expressed as:

$q_{n}\left(x_{1}, x_{2}, t\right)=\sum_{n=1}^{\infty} \sum_{m=1}^{\infty} Q_{m n}(t) \sin \frac{m \pi x_{1}}{a} \sin \frac{n \pi x_{2}}{b}$

$Q_{m n}$ represents terms of the Fourier series and for a concentrated load at a point $\left(x_{1}^{c}, x_{2}^{c}\right)$, it is expressed as:

$Q_{m n}(t)=\frac{4 F(t)}{a b} \sin \frac{m \pi x_{1}^{c}}{a} \sin \frac{n \pi x_{2}^{c}}{b}, m, n=1,3,5 \ldots$

By substituting equations (6) to (10) in equations (1) to (5), the following relationship is obtained:

$\left[\begin{array}{lllll}c_{11} & c_{12} & c_{13} & c_{14} & c_{15} \\ c_{12} & c_{22} & c_{23} & c_{24} & c_{25} \\ c_{13} & c_{23} & c_{33} & c_{34} & c_{35} \\ c_{14} & c_{24} & c_{34} & c_{44} & c_{45} \\ c_{15} & c_{25} & c_{35} & c_{45} & c_{55}\end{array}\right]\left\{\begin{array}{l}U_{m n}(t) \\ V_{m n}(t) \\ W_{m n}(t) \\ X_{m n}(t) \\ Y_{m n}(t)\end{array}\right\}=\left\{\begin{array}{c}0 \\ 0 \\ \rho h \ddot{W}_{m n}(t)-Q_{m n}(t) \\ 0 \\ 0\end{array}\right\}$

The equations of $c_{i j}$ are described in [19]

Equation (13) can be simplified as:

$\ddot{W}_{m n}(t)+\omega_{m n}^{2} W_{m n}(t)=\frac{Q_{m n}(t)}{\rho h}$

$\omega_{m n}$ is broken down into three separate natural frequencies in order to incorporate variable stiffness top face-sheets for a sandwich plate with three variable stiffness sections (either core 
or face-sheets or a combination). A typical geometry of this nature is shown in Case D under section 4.4. For a variable stiffness top facesheet model, natural frequencies are expressed as:

Natural frequency of top face-sheet section 1.

$\omega_{m n_{1}}^{2}=\frac{-\left(c_{13_{2}} K_{U_{2}}+c_{23_{2}} K_{V_{2}}+c_{33_{2}}+c_{34_{2}} K_{X_{2}}+c_{35_{2}} K_{Y_{2}}\right)}{\rho t_{t_{1}}}$

Natural frequency of top face-sheet section 2.

$\omega_{m n_{2}}^{2}=\frac{-\left(c_{13_{2}} K_{U_{2}}+c_{23_{2}} K_{V_{2}}+c_{33_{2}}+c_{34_{2}} K_{X_{2}}+c_{35_{2}} K_{Y_{2}}\right)}{\rho t_{t_{2}}}$

Natural frequency of top face-sheet section 3.

$\omega_{m n_{3}}^{2}=\frac{-\left(c_{13_{3}} K_{U_{3}}+c_{23_{3}} K_{V_{3}}+c_{33_{3}}+c_{34_{3}} K_{X_{3}}+c_{35_{3}} K_{Y_{3}}\right)}{\rho t_{t_{3}}}$

Then, the dynamic contact stiffness of the top face-sheet for section 1,2 and 3 can be determined from:

$K_{1 d_{1}}=\omega_{m n_{1}}^{2} M_{f_{1}}$

$K_{1 d_{2}}=\omega_{m n_{2}}^{2} M_{f_{2}}$

$K_{1 d_{3}}=\omega_{m n_{3}}^{2} M_{f_{3}}$

Effective dynamic contact stiffness of top facesheet with three different thicknesses can be expressed as:

$K_{1 d_{e f}}=K_{1 d_{1}}+K_{1 d_{2}}+K_{1 d_{3}}$

The effective mass of face-sheet for a core with three equally spaced variable stiffness cores are defined as:

$$
\begin{aligned}
& M_{f_{1}}=\frac{4 R^{2}}{25}\left[25+\left(1-\frac{a / 3}{2 R}\right)^{2}\right] \rho_{f} t_{t_{1}} \\
& M_{f_{2}}=\frac{4 R^{2}}{25}\left[25+\left(1-\frac{a / 3}{2 R}\right)^{2}\right] \rho_{f} t_{t_{2}} \\
& M_{f_{3}}=\frac{4 R^{2}}{25}\left[25+\left(1-\frac{a / 3}{2 R}\right)^{2}\right] \rho_{f} t_{t_{3}}
\end{aligned}
$$




\section{Stiffness matrices of sandwich plates}

The main novelty of the study is the analysis of variable stiffness face-sheets and cores on the impact response of curved sandwich plates. The global stiffness matrices are different for the sandwich panel with variable stiffness facesheets and cores as shown in Table 1 . These matrices are evaluated on the assumption that thickness of the core remain constant under loading and that in-plane stiffness of the core are negligible [20]. Stiffness matrices of the face-sheet and sandwich plate have an effect on the natural frequency of the facesheets and dynamic global stiffness of the sandwich plate. The stiffness matrices are modified to adopt for sandwich plates with varying core heights and facesheet thicknesses. These stiffness matrix values are used in the calculation of the effective dynamic global stiffness of the sandwich plate. Table 1 shows the stiffness matrices of a sandwich plate with three variable core sections.

\begin{tabular}{|c|c|c|c|}
\hline $\begin{array}{l}\text { Stiffness matrix of } \\
\text { sandwich plate }\end{array}$ & Section 1 & Section 2 & Section 3 \\
\hline$\left[\mathbf{A}_{\text {sand }}\right]$ & {$\left[A_{1}\right]^{t}+\left[A_{1}\right]^{b}$} & {$\left[A_{2}\right]^{t}+\left[A_{2}\right]^{b}$} & {$\left[A_{3}\right]^{t}+\left[A_{3}\right]^{b}$} \\
\hline \multirow[t]{4}{*}[\mathbf{B}_{\text{sand}}]{} & {$\left[A_{1}\right]^{t}-d_{b_{1}}\left[A_{1}\right]^{b}$} & {$\left[A_{2}\right]^{t}-d_{b_{2}}\left[A_{2}\right]^{b}$} & {$\left[A_{3}\right]^{t}-d_{b_{3}}\left[A_{3}\right]^{b}$} \\
\hline & $+\left[B_{1}\right]^{t}$ & $+\left[B_{2}\right]^{t}$ & $+\left[B_{3}\right]^{t}$ \\
\hline & T $\left[D_{1}\right]$ & $+\left[B_{2}\right]^{b}$ & $+\left[B_{3}\right]^{b}$ \\
\hline & $+\left[B_{1}\right]^{b}$ & & \\
\hline \multirow[t]{4}{*}[D_{\text{sand}}]{} & $\left(d_{t_{1}}\right)^{2}\left[A_{1}\right]^{t}$ & $\left(d_{t_{2}}\right)^{2}\left[A_{2}\right]^{t}$ & $\left(d_{t_{3}}\right)^{2}\left[A_{3}\right]^{t}$ \\
\hline & $+\left(d_{b_{1}}\right)^{2}\left[A_{1}\right]^{b}+\left[D_{1}\right]^{t}$ & $+\left(d_{b_{2}}\right)^{2}\left[A_{2}\right]^{b}+\left[D_{2}\right]^{t}$ & $+\left(d_{b_{3}}\right)^{2}\left[A_{3}\right]^{b}+\left[D_{3}\right]^{t}$ \\
\hline & $+\left[D_{1}\right]^{b}+2 d_{t_{1}}\left[B_{1}\right]^{t}$ & $+\left[D_{2}\right]^{b}+2 d_{t_{2}}\left[B_{2}\right]^{t}$ & $+\left[D_{3}\right]^{b}+2 d_{t_{3}}\left[B_{3}\right]^{t}$ \\
\hline & $-2 d_{b_{1}}\left[B_{1}\right]^{b}$ & $-2 d_{b_{2}}\left[B_{2}\right]^{b}$ & $-2 d_{b_{3}}\left[B_{3}\right]^{b}$ \\
\hline
\end{tabular}

Table 1. Modified Stiffness matrices of sandwich plates for a plate with three variable stiffness cores

\section{Global force-indentation response of sandwich panel}

For the sandwich plate with variable stiffness core sections, separate dynamic global stiffness are determined for the different sections. In the case of a core with three unequal sections, the total effective dynamic global stiffness of the sandwich plate is expressed as: 
$K_{g d_{e f}}=K_{g d_{1}}+K_{g d_{2}}+K_{g d_{3}}$

where,

$K_{g d_{1}}, K_{g d_{2}}, K_{g d_{3}}$ are dynamic global stiffness's of section 1,2 and 3 of the sandwich plate respectively. The method to obtain dynamic global stiffness of the sandwich plate with a constant stiffness core is given in reference [3]. This technique is applied in obtaining separate dynamic global stiffnesses of the sandwich plate with a variable stiffness core section.

\section{Sandwich plate models}

This paper considers the local indentation of the top face-sheet and core crushing. In a simply supported sandwich plate, two types of deformation occur: the local indentation of the top facesheet into the core material, $\delta$, and the global plate bending and shear deformation, $\Delta$. Most models determined the local indentation through Hertzian contact methods. However, the local deformation considered in this study causes transverse deflections of the entire top face-sheet and core crushing and therefore Hertzian contact laws are invalid in determining the local indentation response. Three consecutive regimes are reflected for the local indentation of the plate. I- Plate on elastic foundation; II- Plate on a rigid-plastic foundation; III- Membrane on a rigid-plastic foundation. The plate on an elastic foundation can be used to determine the indentation response when the indentation is very small. The plate on rigid-plastic foundation can be used as the face sheet indentation becomes larger, but still less than half the thickness of the plate. The membrane on a rigid plastic foundation is used to find the indentation response when the face sheet indentation is greater than the face sheet thickness. The local indentation response of a simply supported plate on an elastic foundation is presented by Eq. 26 .

$$
\begin{aligned}
& \delta_{\mathrm{mn}} \\
& =\sum_{\mathrm{m}=1,3, \ldots}^{\infty} \times \sum_{\mathrm{n}=1,3, \ldots}^{\infty}\left\{\left\{4 \mathrm{P} \sin \left(\frac{\mathrm{m} \pi}{2}\right) \sin \left(\frac{\mathrm{n} \pi}{2}\right)\right\} /\left\{\mathrm{a}^{2}\left[\frac{\pi}{\mathrm{a}^{4}}\left(\mathrm{D}_{11} \mathrm{~m}^{4}+2\left(\mathrm{D}_{12}+2 \mathrm{D}_{66}\right) \mathrm{m}^{2} \mathrm{n}^{2}+\mathrm{D}_{22} \mathrm{n}^{4}\right)+\mathrm{k}^{\mathrm{c}}\right]\right\}\right\}
\end{aligned}
$$

The present model is capable of predicting top facesheet failure and core crushing, but not the damage in bottom facesheet at higher impact energies. Thus, the analytical method is only valid for low impact energies. 
Different cases of sandwich plate geometry are studied. In all models, length, width and curvature are constant.

\subsection{Case A (Constant stiffness face-sheet and core model)}

The first case which is the baseline model involves a sandwich plate geometry with the constant thickness top and bottom facesheets.

- $t_{t}=t_{b}$

- Constant stiffness core with thickness, c

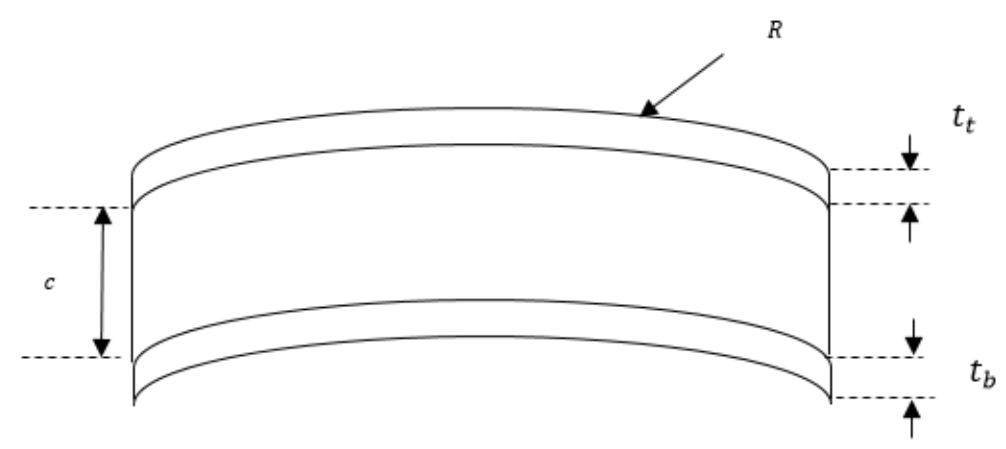

Figure 2. Schematic for constant top/bottom facesheet and constant thickness core

\subsection{Case B (Unequal top and bottom face-sheets)}

In this case, total thickness of the top facesheet is changed, keeping bottom facesheet thickness constant. Core thickness is constant

$t_{t}<t_{b}$ or $t_{t}>t_{b}$

\subsection{Case C (Variable stiffness core model)}

In this model, thickness of facesheets are equal with varying core height across the width of the plate. This type of geometry is shown in Figure 3. The main parameter changed here is the thickness of the centre core section that is subjected to the impact. It is assumed that in the case of the plate with three varying stiffness cores, they are equally spaced (see Figure 3 ). 
- $t_{t}=t_{b}$

- $\quad c_{2}>c_{1}$ and $c_{2}<c_{1}$

$d_{t}$ is the distance from centre of core section to the mid plane of the facesheet.

$$
\begin{aligned}
& d_{t 1}=\frac{c_{1}}{2}+\frac{t_{t}}{2} \\
& d_{t 2}=\frac{c_{2}}{2}+\frac{t_{t}}{2} \\
& d_{t 3}=\frac{c_{3}}{2}+\frac{t_{t}}{2}
\end{aligned}
$$
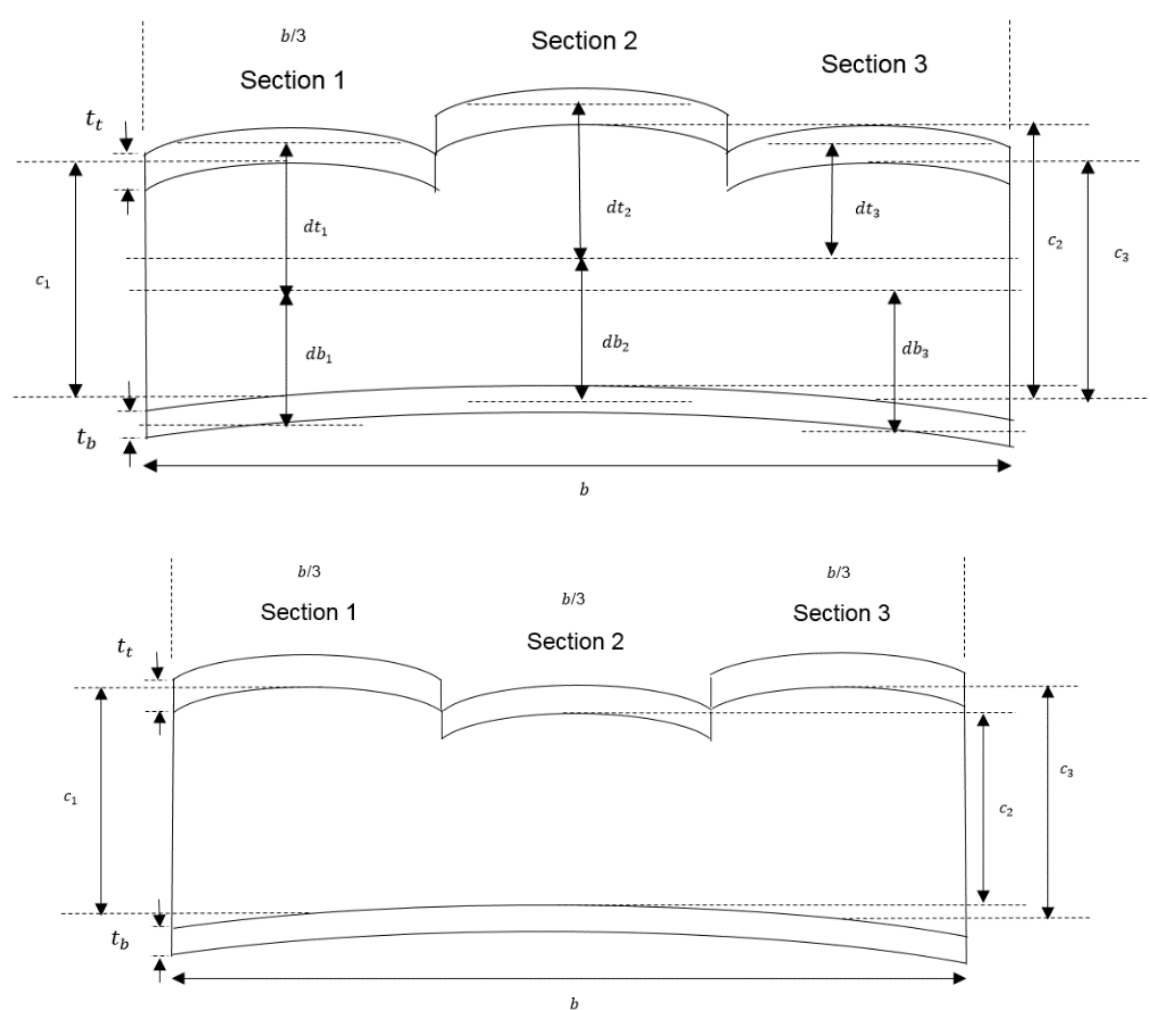

Figure 3. Schematic for constant top/bottom facesheet and variable thickness core.

\subsection{Case D (Variable stiffness top face-sheet model)}

In this model, the stiffness of the facesheet of centre section subjected to impact loading is varied by changing its thickness. Height of core is constant.

$t_{t_{2}}>t_{t_{1}}$ and $t_{t_{2}}<t_{t_{1}}$ 


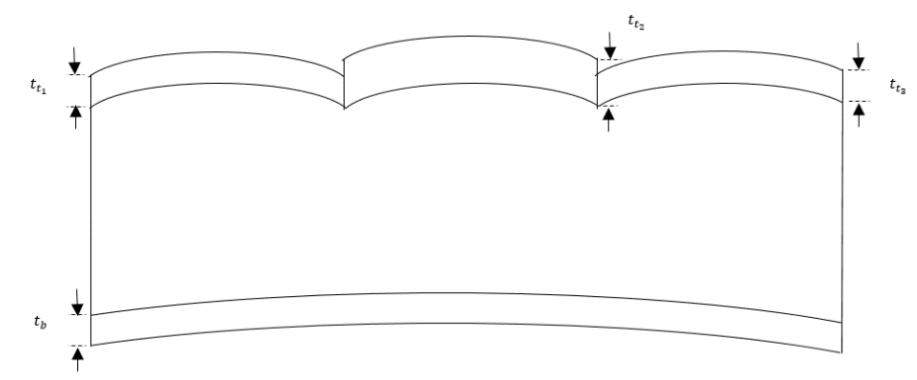

Figure 4. Schematic for variable top facesheet with constant core section.

\section{Low velocity impact of simply supported plates}

This section describes the analytical models for predicting the impact response of simply supported sandwich plates. This model introduces an effective dynamic global stiffness of the facesheet and sandwich plate, $K_{1 d_{e f}}$ and $K_{g d_{e f}}$ respectively. Therefore, this model is applicable for sandwich plates with variable stiffness facesheets and core sections.

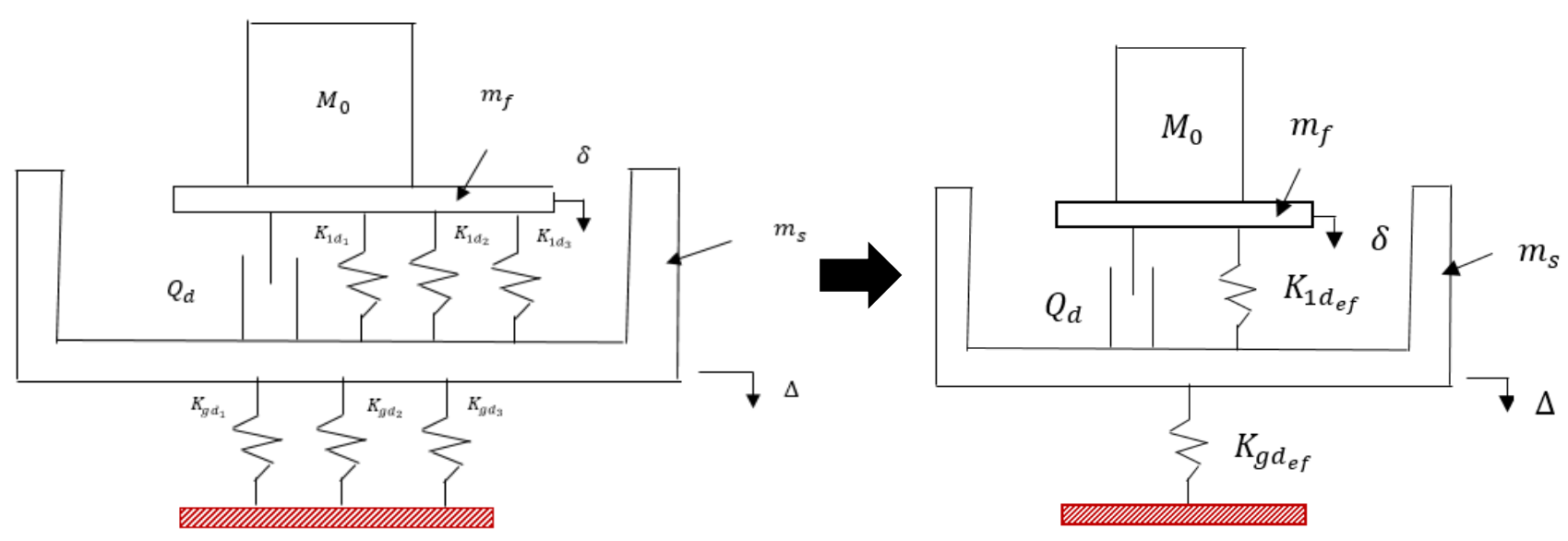

Figure 5. Modified two degree of freedom spring-mass-dashpot system for three section variable stiffness facesheet and core plates.

Both local and global deflections occur for a simply supported plate. A two degree of freedom system is used to derive the function for the contact force (Figure 5).

Two degree-of-freedom system equations of motion are expressed as:

$\left(M_{0}+m_{f}\right)(\ddot{\Delta}+\ddot{\delta})+P_{1}(\delta)+Q_{d}=0$

and 
$Q_{d}+P_{1}(\delta)=m_{s} \ddot{\Delta}+K_{g d_{e f}} \Delta$

By linearizing the local spring response

$P_{1}(\delta) \approx K_{1 d_{e f}} \delta$

The equations (30) and (31) can be simplified by assuming that the mass of the sandwich panel is insignificant related to the mass of the hemispherical impactor.

$M_{0}\left(\ddot{\Delta}+\ddot{\delta}+K_{1 d_{e f}} \delta+Q_{d}=0\right)$

and

$Q_{d}+K_{1 d_{e f} \delta} \delta K_{g d_{e f}} \Delta$

Total Dynamic core crushing strength, Qd is defined by:

$Q_{d}=\pi R^{2} q_{d}$

where $q_{d}$ is dynamic crushing strength. Compressive strength of the core is determined experimentally and this value is $q_{d} . R$ is radius of projectile.

Differentiating both sides two times respect to time $t$ gives:

$\ddot{\Delta}=\frac{K_{1 d_{e f}}}{K_{g d_{e f}}} \ddot{\delta}$

Substituting $\ddot{\Delta}$ into equation (33) gives:

$M_{0}\left(1+\frac{K_{1 d_{e f}}}{K_{g d_{e f}}}\right) \ddot{\delta}+K_{1 d_{e f}} \delta+Q_{d}=0$

Equation (37) is subjected to initial conditions $\dot{\delta}(0)=\dot{\delta}_{0}=K_{g d} V_{0} /\left(K_{g d_{e f}}+K_{1 d_{e f}}\right)$ and $\delta(0)=0$

The solution for $\delta$ is given by:

$\delta=\frac{\dot{\delta}_{0}}{\omega_{e f f}} \sin \omega_{e f f} t+\frac{Q_{d}}{K_{1 d_{e f}}} \cos \omega_{e f f} t-\frac{Q_{d}}{K_{1 d_{e f}}}$

For a sandwich plate with three varying stiffness sections:

$\omega_{\text {eff }}=\omega_{1}+\omega_{2}+\omega_{3}$

where, $\omega_{1}$ frequency of vibration of section 1 sandwich plate, $\omega_{2}$ frequency of vibration of section 2 of sandwich plate, $\omega_{3}$ frequency of vibration of section 3 of whole sandwich plate 
where $\omega_{\text {eff }}$ which is effective frequency of vibration due to impact for the whole sandwich plate is:

$\omega_{e f f}=\int_{0}^{1 / 3 b} \sqrt{\frac{K_{1 d_{1} K g d_{1}}}{\left(K_{1 d_{1}}+K_{g d_{1}}\right) M_{0}}}+\int_{1 / 3 b}^{2 / 3 b} \sqrt{\frac{K_{1 d_{2} K_{g d_{2}}}}{\left(K_{1 d_{2}}+K_{g d_{2}}\right) M_{0}}}+\int_{2 / 3 b}^{b} \sqrt{\frac{K_{1 d_{3} K g d_{3}}}{\left(K_{1 d_{3}}+K_{g d_{3}}\right) M_{0}}}$

$\omega_{\text {eff }}$ also considers the position of the variable stiffness section in the top facesheet.

The impact force is expresses as:

$$
\begin{aligned}
& F(t)=-M_{0}(\Delta+\delta)=-M_{0}\left(1+\frac{K_{1 d_{e f}}}{K_{g d_{e f}}}\right) \ddot{\delta} \\
& \dot{\delta}=\dot{\delta}_{0} \cos \omega_{e f f} t-\omega_{e f f} \frac{Q_{d}}{K_{1 d_{e f}}} \sin \omega_{e f f} t \\
& \ddot{\delta}=-\omega_{e f f} \dot{\delta}_{0} \sin \omega_{e f f} t-\omega_{e f f}{ }^{2} \frac{Q_{d}}{K_{1 d_{e f}}} \cos \omega_{e f f} t
\end{aligned}
$$

Therefore, expression for the impact force is expressed as:

$\mathrm{F}(\mathrm{t})=-\mathrm{M}_{0}\left(1+\frac{K_{1 d_{e f}}}{K_{g d_{e f}}}\right)\left(-\omega_{e f f} \delta_{0} \sin \omega_{e f f} \mathrm{t}\right)-\frac{\mathrm{Q}_{\mathrm{d}} \omega_{e f f^{2}}}{\mathrm{~K}_{1 \mathrm{~d}}} \cos \omega_{e f f} \mathrm{t}$

where,

$\dot{\delta}_{0}=\frac{V_{0} K_{g d_{e f}}}{\left(K_{g d_{e f}}+K_{1 d_{e f}}\right)}$

\section{Validation of the developed analytical models}

The present analytical model is first validated with experimental work performed by Yurddaskal and Baba [16] performed experimental studies on low velocity impact response of foam based curved sandwich plates. In the calculation of the effective dynamic global stiffness, $K_{g d_{e f}}$ of the panel, the equations for the simply supported boundary conditions were used. It is noted that in the proposed analytical model, only top face-sheet damage is considered. In reality, the bottom face-sheet could also be damaged at higher impact energies, thus resulting in two force drops in contact force history plots. Therefore, the present analytical model is applicable at very low impact energies. Material and geometrical properties of face-sheets, core and impactor are presented in Tables 2-4. These properties are the initial baseline for the analytical model and corresponds to Case A of the impact models in section 4. 


\begin{tabular}{rc}
\hline Material Property & Ref (16) \\
\hline $\mathrm{E}_{11}(\mathrm{GPa})$ & 31 \\
$\mathrm{E}_{22}(\mathrm{GPa})$ & 12 \\
\hline $\mathrm{E}_{33}(\mathrm{GPa})$ & 12 \\
\hline $\mathrm{G}_{12}(\mathrm{GPa})$ & 3.2 \\
\hline $\boldsymbol{v}_{\mathbf{1 2}}$ & 0.3 \\
\hline LTS $(\mathrm{MPa})$ & 706 \\
\hline TTS $(\mathrm{MPa})$ & 123 \\
\hline LCS $(\mathrm{MPa})$ & 472 \\
\hline TCS $(\mathrm{MPa})$ & 183 \\
\hline SS $(\mathrm{MPa})$ & 77
\end{tabular}

Table 2. Material properties of uni-directional E-glass/epoxy face-sheet [16].

$$
\text { Properties Ref(16) }
$$

\begin{tabular}{cc}
\hline Density $\left(\mathrm{kg} / \mathrm{m}^{3}\right)$ & 60 \\
\hline Compressive strength (MPa) & 0.90 \\
\hline Compressive Modulus (MPa) & 69 \\
\hline Tensile strength (MPa) & 1.3 \\
\hline Tensile Modulus (MPa) & 45 \\
\hline Shear strength (MPa) & 0.85 \\
\hline Shear Modulus (MPa) & 22
\end{tabular}

Table 3. Mechanical properties of Airex C70.55 foam core [16].

\begin{tabular}{lc}
\hline Properties & Ref $(16)$ \\
\hline Core thickness $(\mathrm{mm})$ & 15 \\
\hline Total ply thickness $(\mathrm{mm})$ & 0.75 \\
\hline Ply orientation & {$\left[90^{\circ} / 45^{\circ} / 45^{\circ} / 90^{\circ}\right]$} \\
\hline Length of panel $(\mathrm{mm})$ & 100 \\
\hline Width of panel $(\mathrm{mm})$ & 100 \\
\hline
\end{tabular}


Table 4. Geometrical properties of facesheets and core.

\begin{tabular}{cc}
\hline Property & Ref (16) \\
\hline Mass $(\mathrm{kg})$ & 4.926 \\
\hline Diameter $(\mathrm{mm})$ & 12.7 \\
\hline $\begin{array}{c}\text { Velocity }(\mathrm{m} / \mathrm{s}) \text { at 10J } \\
\text { impact energy }\end{array}$ & 2.1 \\
\hline
\end{tabular}

Table 5. Dimensions and loading conditions of the impactor.

In this experimental study, the plate was impacted at $10 \mathrm{~J}, 25 \mathrm{~J}$ and $80 \mathrm{~J}$ impact energies. At impact energy of $10 \mathrm{~J}$ corresponding to impact velocity of $2.1 \mathrm{~m} / \mathrm{s}$, only the top facesheet was damaged. The specimens were impacted by a $4.926 \mathrm{~kg}$ hemispherical nose impactor having a $12.7 \mathrm{~mm}$ diameter. The core of the sandwich panel was $15 \mathrm{~mm}$ and radius of the plate were changed within the range of $\mathrm{R}=100$ and $160 \mathrm{~mm}$. Since, data for the maximum contact force were available; it is considered as a method for comparison with the present developed analytical model. As presented in Table 6, the analytical model was proven to be accurate where the difference between the maximum contact force when compared with experimental results was less than $10 \%$ for two instances of plate curvatures (see Figure 6). 


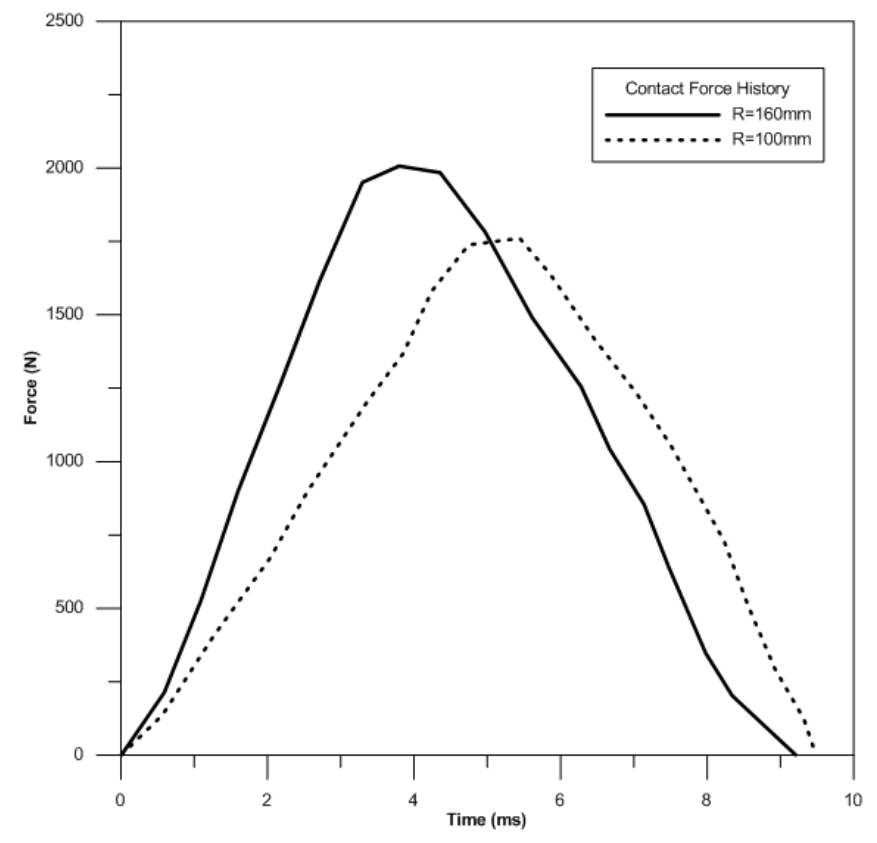

Figure 6. Impact force against time for simply-supported plate with different radius.

Radius (mm) Maximum Impact Force $(N) \quad \%$ difference

\begin{tabular}{lccc}
\hline & Experiment [16] & Present Model & \\
\hline 160 & 2100 & 1990 & $5 \%$ \\
\hline 100 & 1900 & 1750 & $8 \%$ \\
\hline
\end{tabular}

Table 6. Analytical and experimental results comparison.

\section{Parametric studies}

After validating the present model with experimental studies for curved sandwich panels, a parametric study is performed to analyse the effects of different factors affecting the low velocity impact response of curved sandwich panels with foam core. For this study, a foam core plate with glass/epoxy face-sheets are considered. Material properties for the glass/epoxy facesheets and impactor are presented in [16]. The radius of curvature of the panel $160 \mathrm{~mm}$. Boundary conditions of the plate are simply supported. The following sections analyses effects of impact velocity, layups, facesheet thickness (constant and variable thickness), core thickness (constant and variable thickness), and curvature on impact response of the sandwich panel models discussed in section. 


\subsection{Impactor velocity}

In case A, a sandwich plate model were studied with constant facesheet and core thickness. The face-sheets were oriented at $\left[90^{\circ} / 45^{\circ}\right]$ s configuration for each velocities considered in the study. It was observed that the contact duration slightly takes longer when the impact velocity increases. A $20 \%$ increase in velocity gives rise up to $21 \%$ in the impact force and contact time by only $4 \%$. The main reason is related to the initial velocity of top facesheet, $\dot{\partial}_{0}$ which is directly proportional to the impactor velocity (see Figure 7).

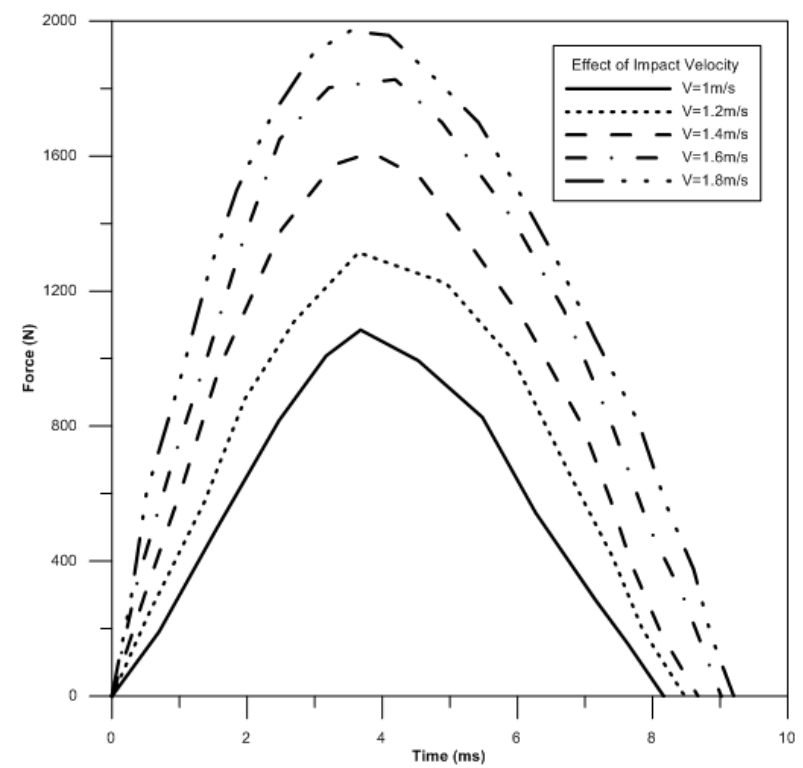

Figure 7. Effect of impactor velocity on impact response.

\subsection{Layups}

The effect of layups presented in Table 6 on the impact response of curved composite sandwich plates in Case A was investigated. The results predicted that the stacking sequence of the facesheets played a minor role in the impact response. Negligible effect was observed in the contact duration. However, the maximum impact force of layup 1 was slightly higher than the other layups. Through the analysis, it is seen that $45^{\circ}$ plies in the laminate increased the maximum contact force, even though interchanging the positions resulted in a negligible change (see Figure 8). The effect of layups have been incorporated into the analytical model by the fact that it has a direct effect on face-sheet stiffness properties, thus it can affect natural frequency and dynamic contact stiffness of the face-sheet. 


\begin{tabular}{cc}
\hline Layup & Fibre Orientation \\
\hline 1 & {$\left[90^{\circ} / 45^{\circ} / 45^{\circ} / 90^{\circ}\right]$} \\
\hline 2 & {$\left[-45^{\circ} / 90^{\circ} / 90^{\circ} /-45^{\circ}\right]$} \\
\hline 3 & {$\left[0^{\circ} / 90^{\circ} / 90^{\circ} / 0^{\circ}\right]$} \\
\hline 4 & {$\left[0^{\circ} / 30^{\circ} / 30^{\circ} / 0^{\circ}\right]$} \\
\hline
\end{tabular}

Table 6. Various layups for the parametric studies.

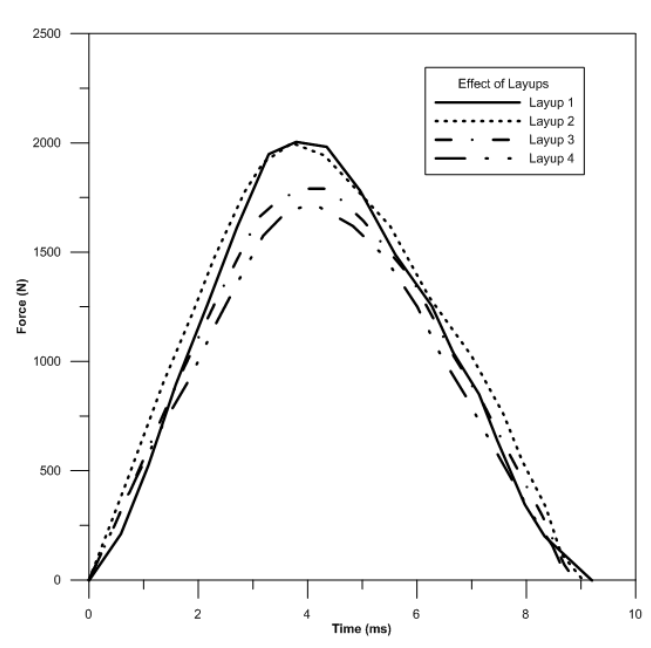

Figure 8. Effect of layups on impact response.

\subsection{Effect of facesheet thickness}

\subsubsection{Constant stiffness facesheets and core (Case A)}

Facesheet thickness also plays a key role in impact response of sandwich panels. In all studies, four facesheets were used with the thickness of ply changed keeping the orientation constant. Higher facesheet thicknesses results in greater maximum contact force and lesser contact duration. For instance, a 33\% increase in facesheet thickness results in a $17 \%$ rise in impact force and 5\% decrease in contact duration. It is also noted that the drop in the maximum contact force occurs earlier when at higher thicknesses. This force drop implies failure of the top face- 
sheet and therefore confirms that thicker face-sheets fail quickly since higher energy is absorbed during the impact (see Figure 9).

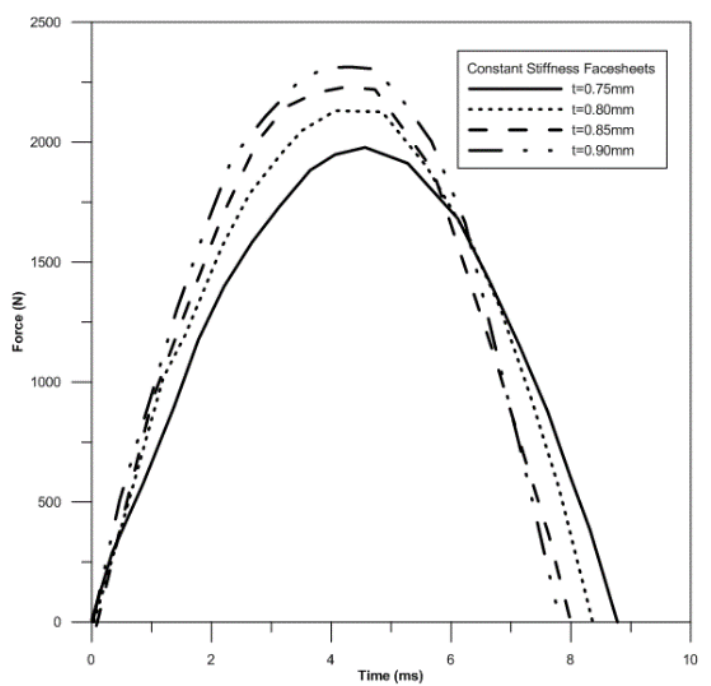

Figure 9. Effect of facesheet thickness on impact response for constant stiffness facesheet and core model (Case A).

\subsubsection{Unequal thickness top and bottom facesheets (Case B)}

The effect of unequal thickness face-sheets are analysed in this section. This corresponds to Case B of the sandwich plate models. In this analysis, total thickness of the top and bottom facesheets are varied as shown in Table 7. It is observed that both top and bottom facesheet contributes to the overall stiffness of the sandwich panel. Increase of thickness gives rise to an enhancement of stiffness. Combinations 2 and 3 corresponds to decrease of top facesheet thickness and combinations 4 and 5 corresponds to decrease of bottom facesheet thickness. The analysis proves that the top facesheet thickness has a greater effect on the maximum contact force than the bottom facesheet thickness. This is demonstrated by the higher drop in maximum contact force when compared with the sandwich panel with constant thickness facesheets. A $0.1 \mathrm{~mm}$ reduction in thickness of only top facesheet reduces impact force by $4.9 \%$ whereas $0.1 \mathrm{~mm}$ reduction in thickness of only bottom facesheet gives a $1.4 \%$ reduction in maximum impact force.

\begin{tabular}{ccccc}
\hline Combination & $\begin{array}{c}\text { Top facesheet } \\
\text { thickness }(\mathrm{mm})\end{array}$ & $\begin{array}{c}\text { Bottom facesheet } \\
\text { thickness }(\mathrm{mm})\end{array}$ & $\begin{array}{c}\text { Maximum } \\
\text { contact force/N }\end{array}$ & $\begin{array}{c}\% \text { decrease in } \\
\text { maximum } \\
\text { contact force }\end{array}$ \\
\hline $\begin{array}{c}1 \text { (Constant } \\
\text { thickness } \\
\text { facesheets) }\end{array}$ & 0.75 & 0.75 & 1978 & - \\
\hline
\end{tabular}




\begin{tabular}{|c|c|c|c|c|}
\hline $\begin{array}{l}2 \text { (Top facesheet } \\
\text { thickness }<\text { Bottom } \\
\text { facesheet thickness) }\end{array}$ & 0.65 & 0.75 & 1880 & $4.9 \%$ \\
\hline $\begin{array}{l}3 \text { (Top facesheet } \\
\text { thickness }<\text { Bottom } \\
\text { facesheet thickness) }\end{array}$ & 0.55 & 0.75 & 1700 & $14 \%$ \\
\hline $\begin{array}{c}4 \text { (Top facesheet } \\
\text { thickness }>\text { Bottom } \\
\text { facesheet thickness) }\end{array}$ & 0.75 & 0.65 & 1950 & $1.4 \%$ \\
\hline $\begin{array}{l}5 \text { (Top facesheet } \\
\text { thickness }>\text { Bottom } \\
\text { facesheet thickness) }\end{array}$ & 0.75 & 0.55 & 1935 & $2.2 \%$ \\
\hline
\end{tabular}

Table 7. Combinations for unequal thickness top and bottom facesheets.

\subsubsection{Variable stiffness top facesheet and constant stiffness core (Case D)}

Here, the stiffness of the top facesheet is varying across the width of the plate as shown in the model in Case D. The stiffness of the facesheet section subjected to the central impact is varied in this study. Thickness of the adjacent facesheets are kept constant at $0.75 \mathrm{~mm}$ throughout the analysis. The analysis shows that similar to increasing stiffness of the central core section, increasing stiffness of the central facesheet yields higher maximum contact force. Increase of central facesheet thickness to $0.8 \mathrm{~mm}$ improves contact force by $5 \%$ when compared to the same facesheet thickness increase for the constant stiffness facesheet plate.

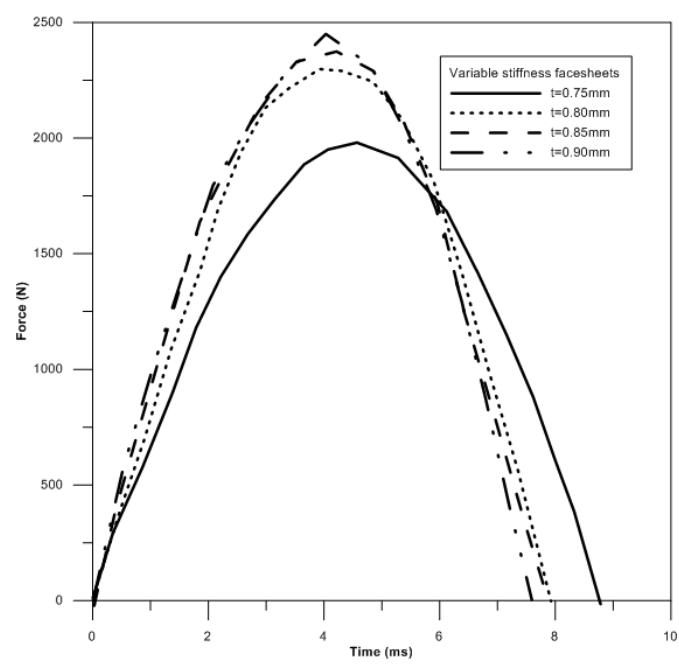

Figure 10. Effect of variable stiffness facesheet thickness on impact response for constant stiffness facesheet and core model (Case D). 


\subsection{Effect of core thickness}

\subsubsection{Constant stiffness core section (Case A)}

The core thickness has also a major contribution to the impact response which is analysed here. As seen from Figure 11, as the core thickness increases, the maximum contact force increases. However, the contact duration decreases. It is also observed that the rise in the contact force decreases as the thickness increases. For instance, as the core thickness is raised from $10 \mathrm{~mm}$ $12.5 \mathrm{~mm}$, the contact force increases by $22 \%$, whereas when it is increased from $17.5 \mathrm{~mm}$ $20 \mathrm{~mm}$, only $4 \%$ increase of contact force is observed. The pattern is similar for the contact duration. Therefore, it is proved that even though the maximum contact force increases with core thickness, it becomes insignificant at higher core thickness values.

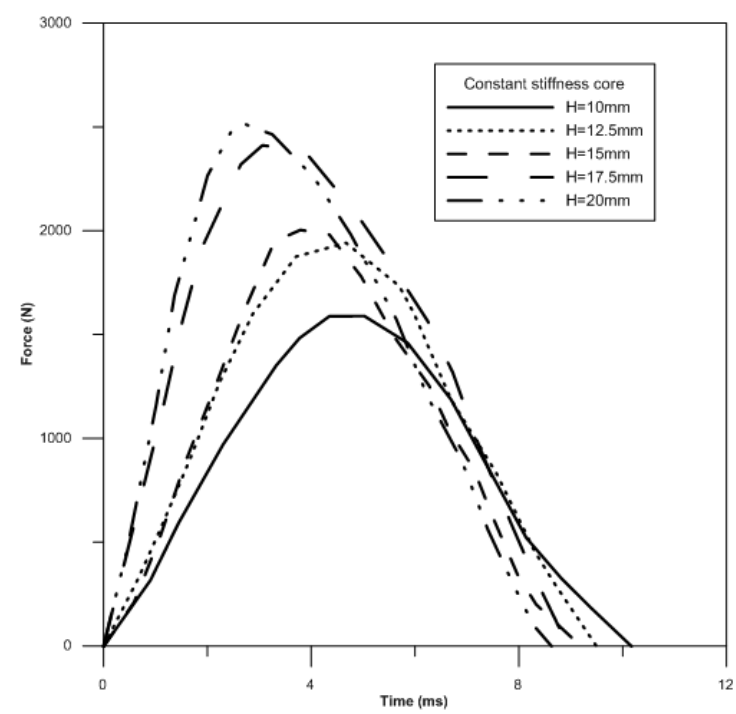

Figure 11. Effect of core thickness on impact response for constant stiffness core plate.

\subsubsection{Variable stiffness core section (Case C)}

In this study, the core is of varying stiffness. This stiffness variation is achieved by changing thickness of the centre core section as shown in Case $\mathrm{C}$ earlier. Thickness of adjacent core sections are kept constant at $15 \mathrm{~mm}$. The results prove that increasing stiffness of the core region subjected to the central impact yields a higher maximum contact force. Increasing core thickness of the centre section to $17.5 \mathrm{~mm}$ yields a maximum contact force which is $10 \%$ higher than increasing thickness of the whole core section to $17.5 \mathrm{~mm}$ as shown in Figure 12. Similarly, 
an increase of core thickness at the centre section to $20 \mathrm{~mm}$ improves maximum contact force by $22 \%$.

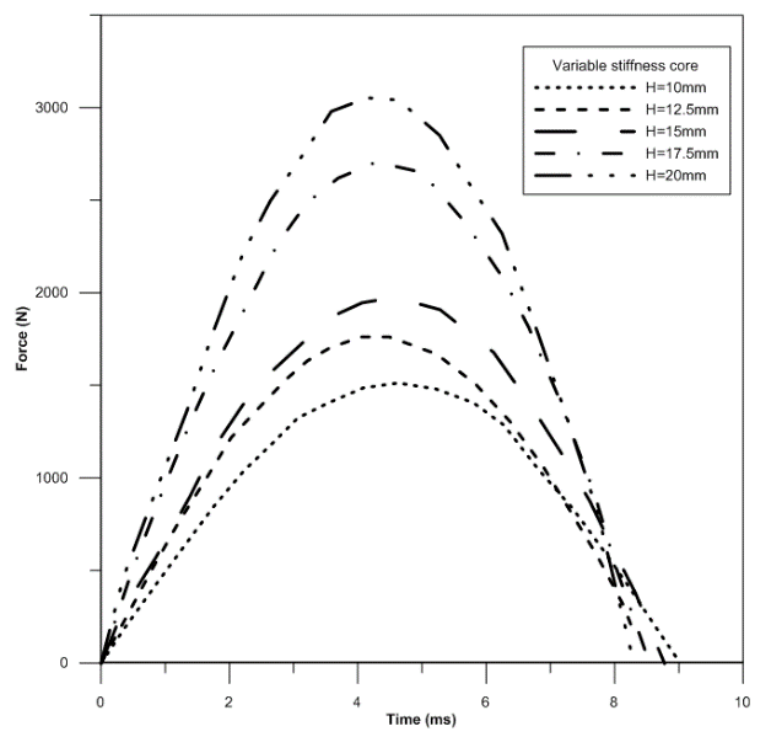

Figure 12. Effect of increasing central core thickness on impact response on variable stiffness plate

\subsection{Effect of sandwich plate curvature (Case A)}

The final parametric study focusses on the effect of panel curvature on the impact response of the curved plate with constant stiffness core section (Case A). Sandwich plate with constant facesheet thickness and core is considered for this study. Results depict that increase of curvature increases the maximum contact force of the plate. The drop in the impact force occurs earlier, thereby indicating that at higher curvatures, the top facesheet fails earlier. A 7\% increase in the plate curvature gives rise to a $5 \%$ rise in the maximum impact force and $2 \%$ decrease in the contact duration (see Figure 13).

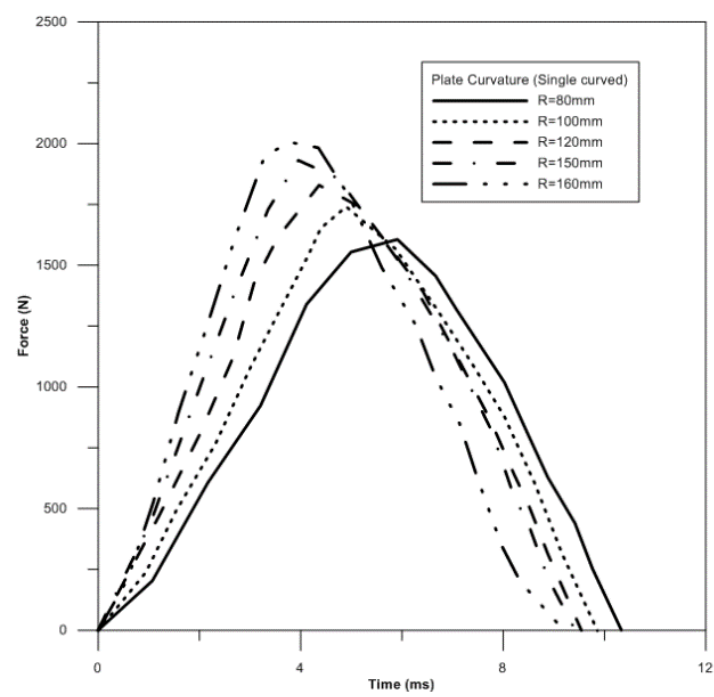

Figure 13. Effect of plate curvature on impact response (Single curvature). 
The present analytical model is also applicable to doubly curved sandwich plates. Therefore, the effect on doubly curvature is also analysed. The analysis proved that double curvature increases maximum impact force of the plate. It was observed that double curvature increases the natural frequency of the top facesheet and this results in an impact force increase. Another observation made is that this increase is higher at larger curvatures. For example, maximum force difference for a plate of $160 \mathrm{~mm}$ (doubly curvature and single curvature) is $9 \%$ when compared with maximum force difference for a plate of $80 \mathrm{~mm}$ (doubly and single) is $4 \%$ as shown in Figure 14.

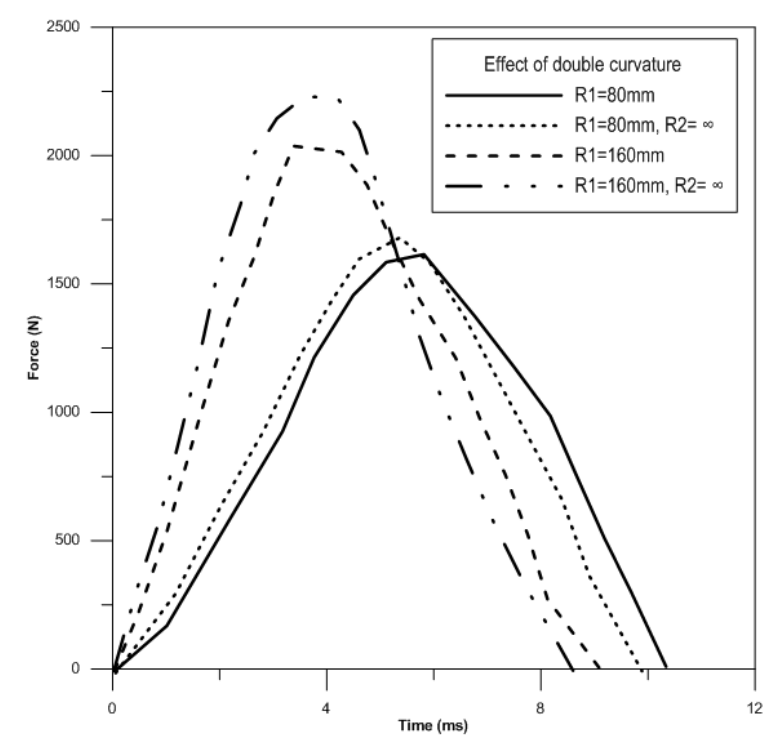

Figure 14. Comparison of single curvature and doubly curved composite sandwich plates.

\section{Validation with Finite Element Modelling}

A numerical finite element model of the curved sandwich plate is developed in finite element program, LS-DYNA. The main aim of this numerical model is to validate the analytical model and compare with available experimental data from impact tests performed by Yurddaskal and Baba [16] for a curved sandwich plate. The facesheets were made using glass/epoxy and modelled using 4-node $1.5 \mathrm{~mm}$ shell elements with Belytschko-Tsay element formulation with four integration points to define the four layers in the facesheet. The foam core is modelled using $2 \mathrm{~mm} \times 2 \mathrm{~mm} \times 2 \mathrm{~mm}$ solid elements similarly to the impactor (see Figure 15a). Material model 54 (ENHANCED_COMPOSITE_DAMAGE) of LS-DYNA was selected to model the intralaminar failure of curved composite plate. The Chang-Chang failure criterion which is the modification of the Hashin's failure criterion was chosen for assessing lamina failure. The postfailure conditions in the Material 54 model are somewhat different from the original Chang- 
Chang equations. In this model four failure modes are categorised. These failure indicators are appointed on total failure for the laminas, where both the strength and the stiffness are set equal to zero after failure is encountered. In this model as described below all material properties of lamina are checked using the following laws to determine the failure characteristic. Material model 54 assesses intra-laminar failure of the composite. Properties of the facesheets are obtained from Table 2. Material model 63 (Crushable Foam) was used to model the core. This material model is used to characterise the properties of isotropic crushable foam and also includes optional damping and a tensile cut-off stress. Stress strain behaviour of the Airex foam core used in the study was entered through a load curve.

The material failure was simulated with the aid of MAT ADD EROSION based on the plastic strain and tensile stress. In the present model, the maximum strain criteria is used without introducing failure in material model, the crushable foam deformation due to the localized force shows problematic furrowing and an unrealistic dent shape as shown in Figure 15. The brittle failure mode cannot be obtained without using an appropriate failure criterion. The existing model was improved to avoid the negative volume error which occurs due the large deformation in the foam. To prevent this error, the stress strain curve was extended exponentially at large strains.

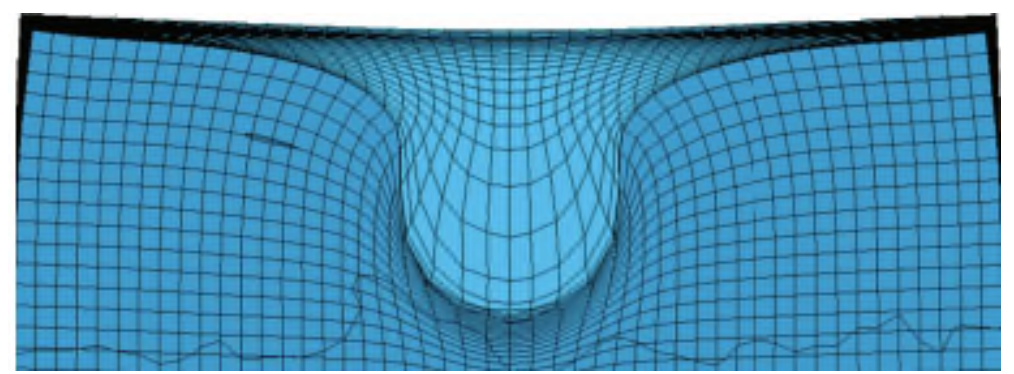

Fig. 15. Deformation of EPS foam without using failure criterion.

Mass of the rigid hemispherical impactor was $4.926 \mathrm{~kg}$ and impact energy was $10 \mathrm{~J}$ corresponding to an impact velocity of $2.1 \mathrm{~m} / \mathrm{s}$. An automatic nodes to surface contact behaviour is defined for contact between the impactor and facesheets. Surface to surface contact was used to bond the facesheets to the foam core. Simply supported boundary conditions were used. In order to prevent negative volume errors due to element distortion, stress-strain curve of foam was exponentially extended at larger strains and one point element solid integration with hourglass control. FE model to investigate effect of variable stiffness cores was also developed (Figure 16). 


\subsection{Constant stiffness core model}

Initially, FE model is developed for the curved sandwich plate with a constant stiffness core. Thickness of the core was $15 \mathrm{~mm}$ similar to the experimental work [16]. Curvature of FE models are constant at $160 \mathrm{~mm}$. The numerical analysis is performed for an impact energy corresponding to $10 \mathrm{~J}$. It is noted that this numerical study corresponds to Case A of the analytical model where curvature, facesheet thickness are kept constant. The comparison between the analytical and numerical model is shown in Figure 16. It is concluded that at an impact energy of $10 \mathrm{~J}(2.1 \mathrm{~m} / \mathrm{s}$ impact velocity) damage is observed only in the top facesheet. The fluctuations in the numerical study depicts the initiation of matrix cracking and the sudden load drop indicates failure of the top facesheet. The maximum contact force difference between the analytical and numerical studies is $7 \%$. A certain level of core crushing was visible from the contact force history plot as shown in Figure 17. It was also observed that only top facesheet damage occurs at low impact energies such as $10 \mathrm{~J}$ (Figure 18).
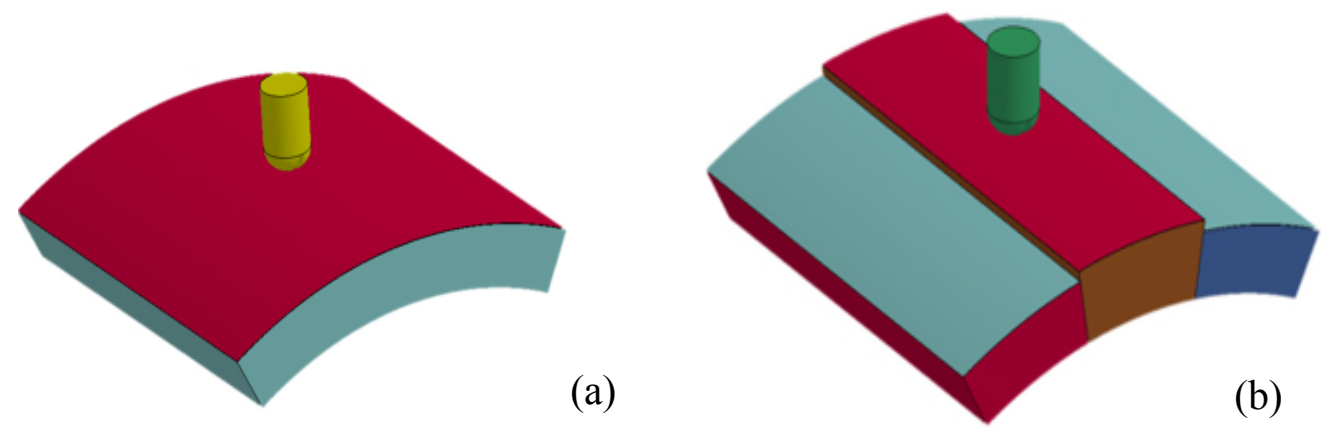

Figure 16. Numerical model (a) constant stiffness core model, (b) variable stiffness core model

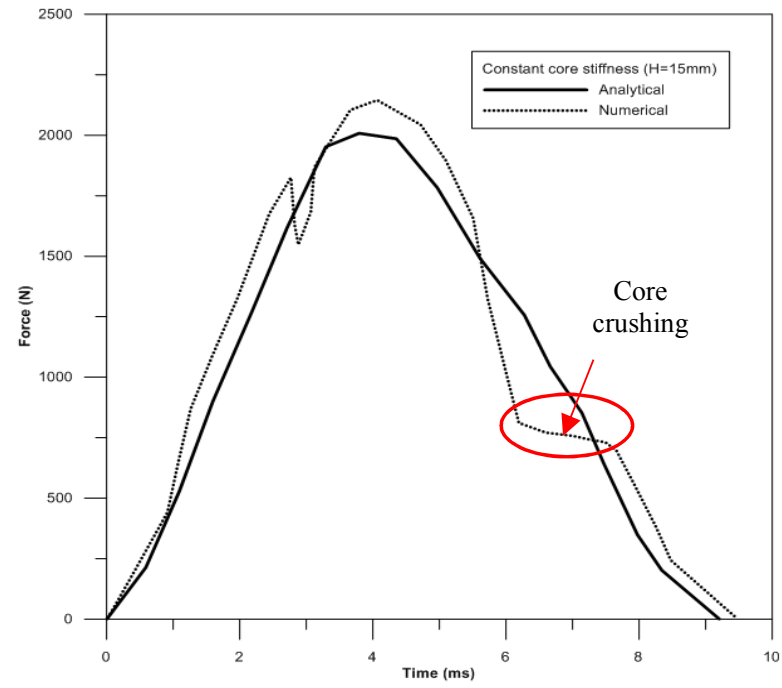

Figure 17. Contact force history comparison for curved sandwich panel of $15 \mathrm{~mm}$ core thickness 

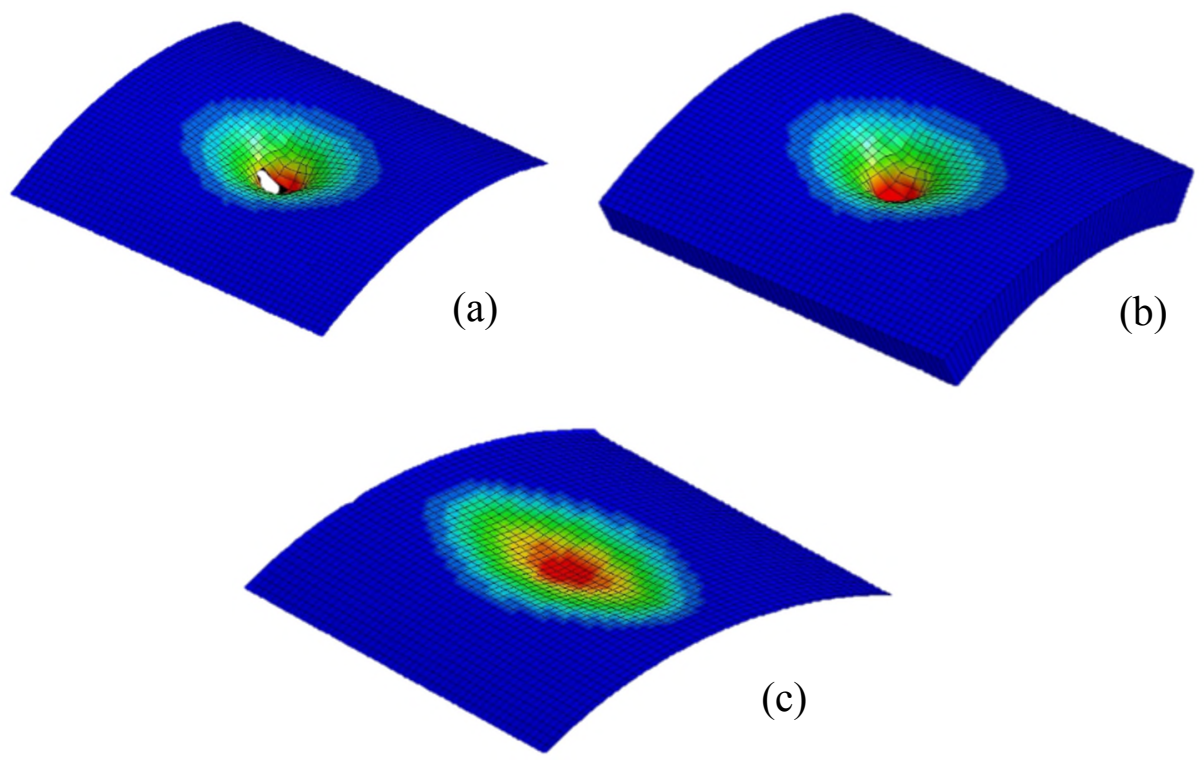

Figure 18. (a) Damage in top facesheet (b) core crushing (c) no damage in bottom facesheet.

Further validation between numerical and analytical models are made by changing the core thickness of the constant stiffness core model. FE models as shown in Figure 18 are developed. Impact energy is kept constant at 10J. Core thicknesses of $10 \mathrm{~mm}, 12.5 \mathrm{~mm}, 17.5 \mathrm{~mm}$ and $20 \mathrm{~mm}$ are investigated. Appreciable comparison was achieved in which the difference between analytical and numerical models were less than 10\%. A certain level of core crushing was observed in the numerical model (see Figures 19 and 20).

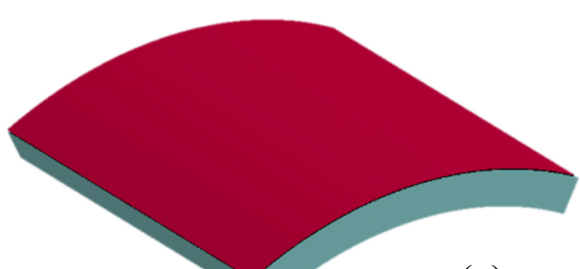

(a)

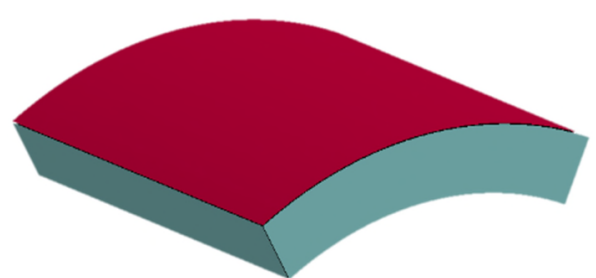

(c)

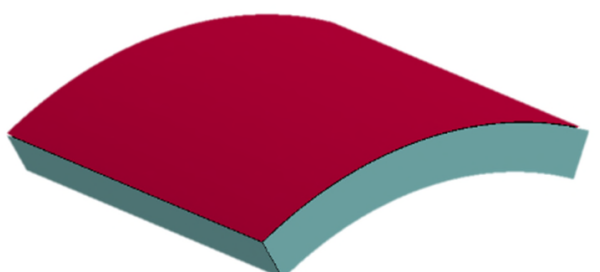

(b)

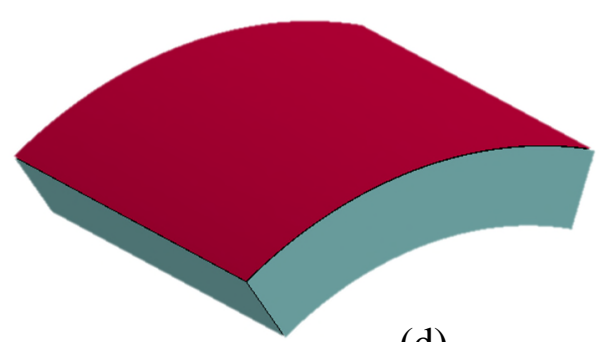

(d)

Figure 19. FE models (a) $\mathrm{H}=10 \mathrm{~mm}$, (b) $\mathrm{H}=12.5 \mathrm{~mm}$, (c) $\mathrm{H}=17.5 \mathrm{~mm}$, (d) $\mathrm{H}=20 \mathrm{~mm}$. 

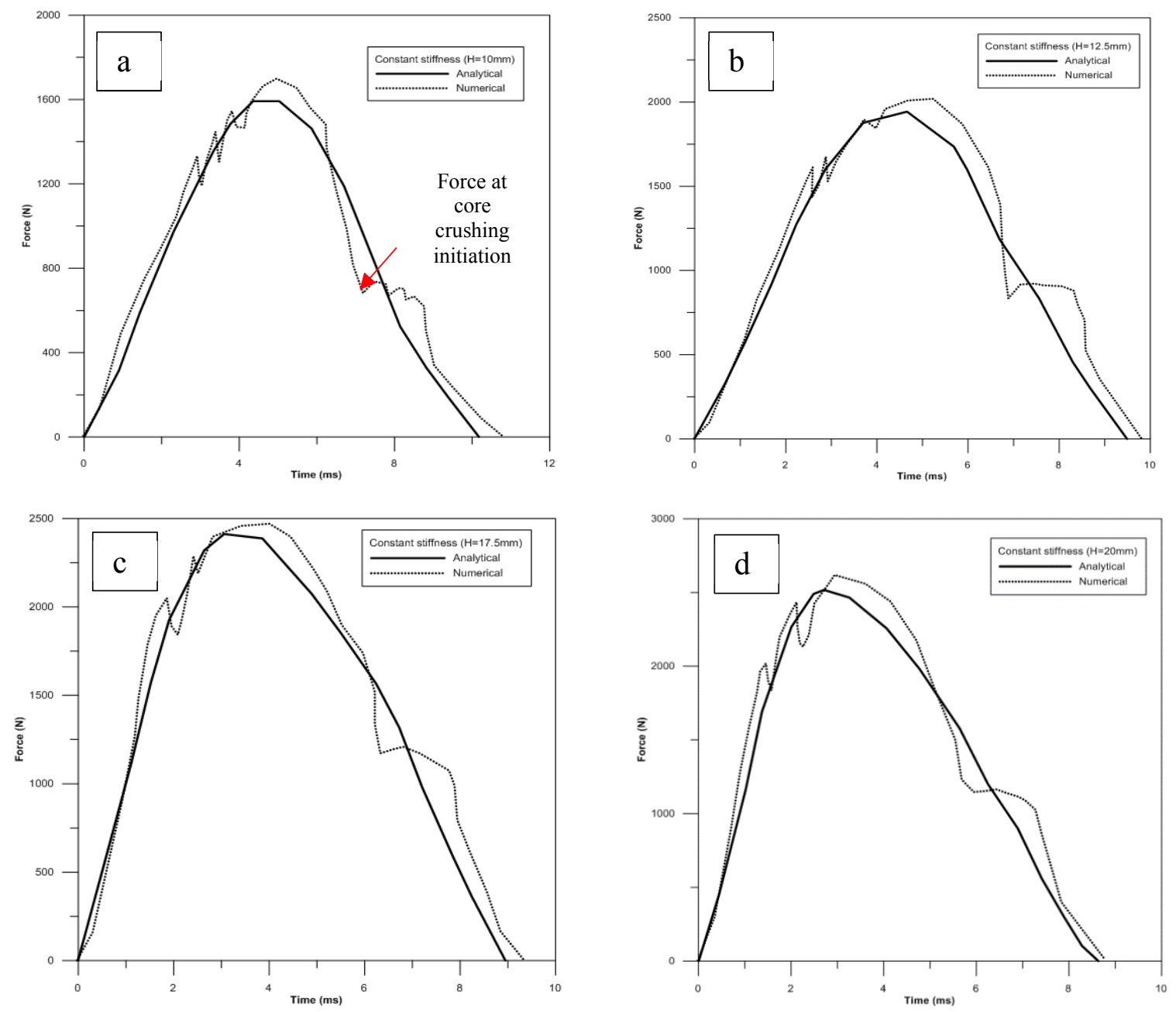

Figure 20. Model validation for constant stiffness core sandwich plate.

\subsection{Variable stiffness core models}

FE models to validate effect of variable stiffness core sections are developed. In the models shown in Figures 21 and 22, the thickness of the mid core section is changed and the adjacent cores are kept constant at $15 \mathrm{~mm}$.
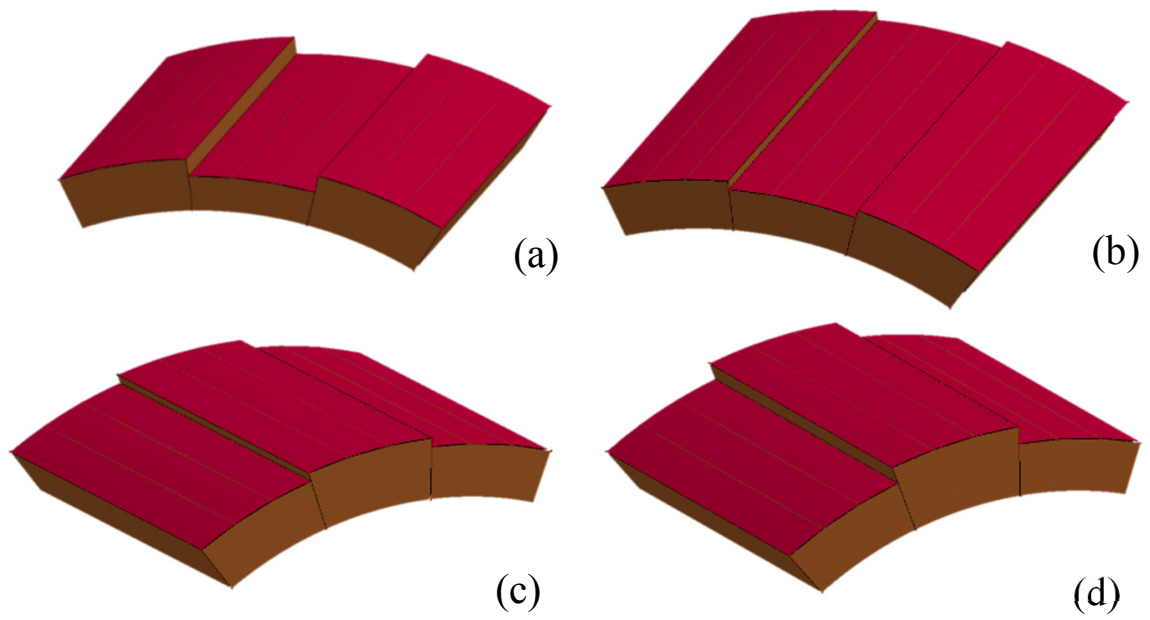
Figure 21. Variable stiffness core sandwich plate. Centre section core thickness is (a) $10 \mathrm{~mm}$, (b) $12.5 \mathrm{~mm}$, (c) $17.5 \mathrm{~mm}$, and (d) $20 \mathrm{~mm}$

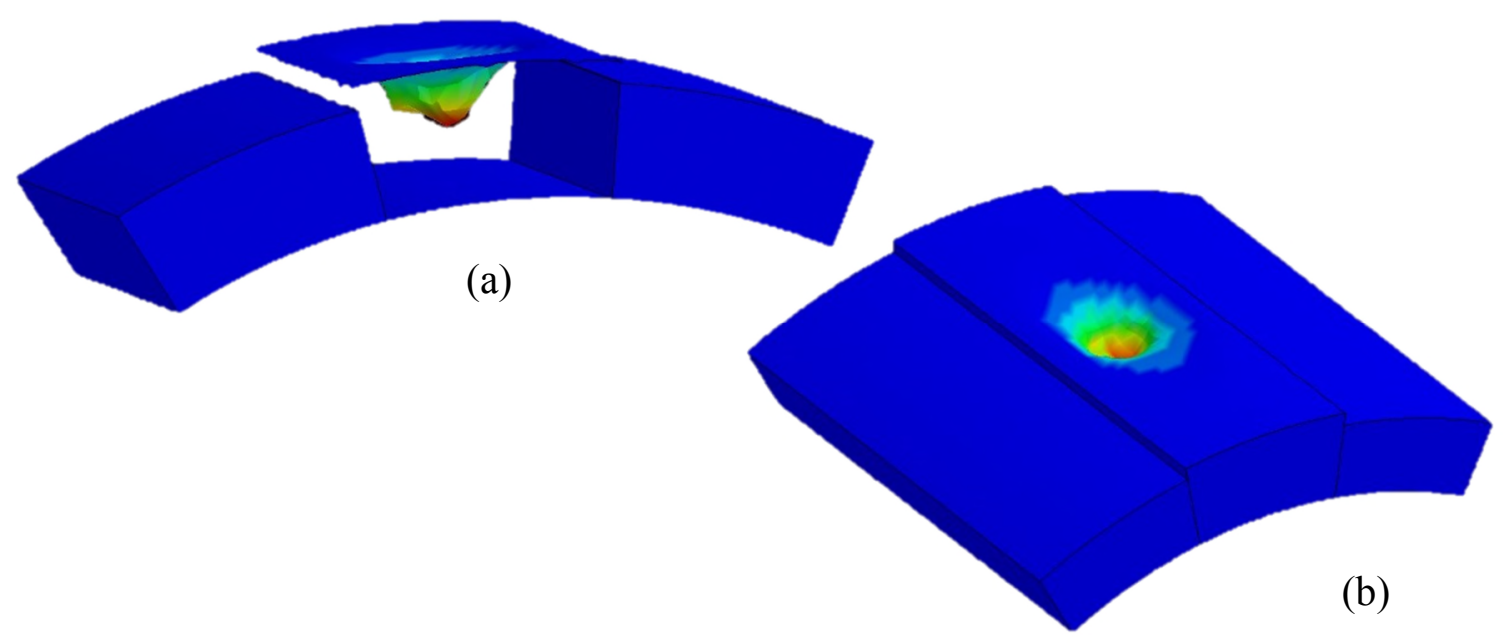

Figure 22. Impact on variable stiffness core curved sandwich plate. (a) top facesheet damage (hiding mid-core section) and (b) core crushing. 
Analysis of results proves that as the core thickness is increased, the maximum contact force at top facesheet failure increases. Larger core thicknesses are able to resist larger impact loads before top facesheet damage occurs and core crushing initiation. This phenomenon is shown in Tables 8 and 9 for both constant stiffness and variable stiffness core sandwich plates. The numerical model also proves that increasing thickness of the centre region of impact has a greater effect on the maximum contact force. For instance, an increase of centre core thickness from $17.5 \mathrm{~mm}$ to $20 \mathrm{~mm}$ increases maximum contact force at top facesheet failure by $12 \%$ when compared to the $6 \%$ increase for the constant stiffness core model. Numerical analysis results shows that contact force at core crushing initiation is higher for plates with greater stiffness at impact location.

\begin{tabular}{cccc}
\hline Model & $\begin{array}{c}\text { Total } \\
\text { Core } \\
\text { thickness } \\
\text { (mm) }\end{array}$ & $\begin{array}{c}\text { Maximum Contact } \\
\text { Force at top facesheet } \\
\text { failure (N) }\end{array}$ \\
\hline & & Analytical & Numerical \\
\hline (a) & 10 & 1590 & 1697 \\
\hline (b) & 12.5 & 1943 & 2020 \\
\hline (d) & 17.5 & 2412 & 2470 \\
\hline (e) & 20 & 2517 & 2620
\end{tabular}

Table 8. Effect of core thickness on top and bottom maximum contact force for constant stiffness core plate.

\begin{tabular}{cccc}
\hline Model & $\begin{array}{c}\text { Centre } \\
\text { Core } \\
\text { thickness } \\
(\mathrm{mm})\end{array}$ & $\begin{array}{c}\text { Maximum Contact } \\
\text { Force at top facesheet } \\
\text { failure }(\mathrm{N})\end{array}$ \\
\hline (a) & 10 & 1512 & 1581 \\
\hline (b) & 12.5 & 1762 & 1990 \\
\hline (d) & 17.5 & 2703 & 2854 \\
\hline (e) & 20 & 3055 & 3206
\end{tabular}

Table 9. Effect of varying centre core thickness on top and bottom maximum contact force for variable stiffness core plate. 


\section{Conclusions}

This paper presented an analytical model to predict the low velocity impact response of curved sandwich plates with a foam core with constant transverse crushing resistance. The impact problem is studied through the use of a modified spring-mass-dashpot model which is modified to incorporate variable stiffnesses of facesheets and cores through use of effective dynamic contact stiffnesses. Transverse flexibility and other important parameters such as the natural frequency of the plate were used in deriving closed form solutions for the low velocity impact analysis. The present analytical model is effectively validated with the experimental and numerical work on curved sandwich plates. A parametric study is performed to study the effects of impactor velocity, stacking sequences, facesheet thickness, core thickness and plate curvatures on the impact response of curved sandwich plates. The analytical model was also extended to study the effect of variable stiffness cores and facesheets on impact response of curved sandwich structures which was the main novelty of this study. It is observed that higher impactor velocities increase the impact force. Stacking sequence of the facesheets have a negligible effect on the impact force and contact duration. Increase of core thickness raises the impact force. The analysis proved that increasing stiffness of the centre core region subjected to impact has a greater effect than increasing stiffness of the whole plate. Similar results were obtained for increasing facesheet stiffness at the impact region. The analysis also proved that top facesheet thickness has a greater effect on impact force than the bottom facesheet and that increase of plate curvature increases energy absorption of curved sandwich structures. Finite element models developed to study impact response of curved foam based sandwich plates validated the analytical models. Contact force at core crushing initiation was higher for plates with greater stiffness at impact location.

\section{References}

[1] Rhodes MD. Impact fracture of composite sandwich structures. In:16 ${ }^{\text {th }}$ Structure, Structural Dynamics and Materials Conference, AIAA Paper No. 75-748;1975. p.1-9.

[2] Schoeppner GA. Low velocity impact response of tension preload composite laminates. In: $10^{\text {th }}$ DOD/NASA/FAA Conference on Fibrous Composites in Structural Design, VIII-47-VIII$61 ; 1994$.

[3] Hoo Fatt M, Park K. Dynamic Models for low-velocity impact damage of composite sandwich Panels-Part A: Deformation. Composite Structures 2001; 52:335-351.

[4] Abrate S. Localized impact on sandwich structures with laminated facings. Appl Mech Rev 1997; 50(2):69-82. 
[5] Hoo Fatt M, Park K. Dynamic Models for low-velocity impact damage of composite sandwich Panels-Part B: Damage Initiation. Composite Structures 2001; 52: 353-364

[6] Malekzadeh K, Khalili MR, Mittal RK. Response of composite sandwich panels with transversely flexible core to low-velocity transverse impact: A new dynamic model. International Journal of Impact Engineering 2007; 34: 522-543.

[7] Caprino G, Teti R. Impact and post-impact behaviour of foam core sandwich structures. J Composite Structures 1994; 29: 47-55.

[8] Anderson TA. An investigation of SDOF models for large mass impact on sandwich composites. Composites Part B 2005; 36(2): 135-42.

[9] Olsson R, McManus HL. Improved theory for contact indentation of sandwich panels. AIAA J 1996; 34:1238-44.

[10] Olsson R. Engineering method for prediction of impact response and damage in sandwich panels. Journal of Sandwich Structures Materials 2002; 4: 3-29.

[11] Frostig Y, Baruch M, Vilnay O, Sheinman I. High-order theory for sandwich beam behaviour with transversely flexible core. Journal of Engineering Mechanics 1992; 118(5):1026-43.

[12] Frostig Y, Baruch M. Free vibrations of sandwich beams with a transversely flexible core: a high order approach. Journal of Sound and Vibrations 1994; 176(2): 195-208.

[13] Flores-Johnson EA, Li QM. Experimental study of the indentation of sandwich panels with carbon fibre-reinforced polymer face sheets and polymeric foam core, Composites Part B, 2011;42:1212-1219.

[14] Hosseini M, Khalili SMR, Malekzadeh Fard K. An indentation law for doubly curved composite sandwich panels with rigid-plastic core subjected to flat-ended cylindrical indenters. Composite Structures 2013; 105: 82-89.

[15] Zhou DW, Stronge WJ. Low velocity impact denting of HSSA lightweight sandwich panel. International Journal of Mechanical Sciences 2006; 48: 1031-45.

[16] Yurddaskal M, Baba OB. The effect of curvature on the impact response of foam-based sandwich composite panels. Steel and Composite Structures 2016; 20(5): 983-997.

[17] Arachchige B, Ghasemnejad H. Theoretical approach to predict the transverse impact response of variable stiffness curved composite plates. Composites Part B 2016; 89: 34-43.

[18] Feng D, Cerioni A, Aymerich F. Structural response and damage resistance of sandwich composites subjected to low velocity impact. $16^{\text {th }}$ European conference on composite materials 2014.

[19] Khalili SMR, Ardali A. Low-velocity impact response of doubly curved symmetric crossply laminated panel with embedded SMA wires. Composite Structures 2013; 105: 216-226.

[20] Kollar L. Mechanics of composite structures 2003. Cambridge University Press. 
2018-06-02

\section{Effect of variable core stiffness on the impact response of curved sandwich plates}

Arachchige, B.

Elsevier

B. Arachchige and H. Ghasemnejad. Effect of variable core stiffness on the impact response of curved sandwich plates. Composite Structures, Volume 200, Issue September, 2018, pp. 565-578 https://doi.org/10.1016/j.compstruct.2018.05.150

Downloaded from Cranfield Library Services E-Repository 